\title{
INTEGRATION AND QUALIFICATION OF THE P-PODS ON THE VEGA MAIDEN FLIGHT
}

\author{
A Thesis \\ presented to \\ the Faculty of California Polytechnic State University, \\ San Luis Obispo
}

\author{
In Partial Fulfillment \\ of the Requirements for the Degree \\ Master of Science in Aerospace Engineering
}

by

Ryan Nugent

December 2016 
(C) 2016

Ryan Nugent

ALL RIGHTS RESERVED 
COMMITTEE MEMBERSHIP

TITLE: Integration and Qualification of The P-PODs

on The Vega Maiden Flight

AUTHOR: Ryan Nugent

DATE SUBMITTED: December 2016

COMMITTEE CHAIR: Jordi Puig-Suari, Ph.D.

Professor of Aerospace Engineering

COMMITTEE MEMBER: $\quad$ Faysal Kolkailah, Ph.D.

Professor of Aerospace Engineering

COMMITTEE MEMBER: Kira Abercromby, Ph.D.

Associate Professor of Aerospace Engineering

COMMITTEE MEMBER: Wenschel Lan, Ph.D.

Naval Postgraduate School 


\begin{abstract}
Integration and Qualification of The P-PODs on The Vega Maiden Flight Ryan Nugent
\end{abstract}

On February 13, 2012, California Polytechnic State University, San Luis Obispo flew three Poly-Picosatellite Orbital Deployers (P-PODs), carrying seven European University CubeSats sponsored by the European Space Agency (ESA), on the Vega Maiden Flight. This was the first time CubeSats shared a ride to space with other payloads on an ESA-owned launch opportunity. In order to meet launch requirements, it must be proven through proper documentation that the P-POD would operate properly and not interfere with the launch vehicle or other payloads on the mission. This thesis outlines the program flow, required documentation, and issues encountered during the launch campaign to get the P-PODs properly qualified and integrated on to the Vega launch vehicle. This mission required Cal Poly to create several unique solutions, which were only implemented for this mission, in order to meet unique technical requirements and programmatic goals. As a result of this mission's success the ESA Education Office implemented the Fly Your Satellite Program, which has continued to support and launch CubeSats developed by European universities. 


\section{ACKNOWLEDGMENTS}

I would like to thanks the European Space Agency's Education Office for creating this opportunity to fly the first CubeSats on an ESA launch vehicle, for using that opportunity for universities, and for partnering with Cal Poly in order to achieve those goals. I would specifically like to thank Piero Galeone for gong above and beyond the call of duty in order to convince ESA this mission was worth it and for having the patience to, not only, work with the European university CubeSat teams but also Cal Poly and our students. This was a great opportunity for myself, as a student and later staff member of Cal Poly, and for all of the other students that were able to travel to Europe and South America to support this mission.

I also have to thank all of the Young Graduate Trainee's of the Education Office that supported this mission. First with Jakob Fromm Pedersen, who was able to convey his knowledge and experience as a university CubeSat develop to the rest of the Education Office at the start of this mission. Also, Jordan Vannitsen for all of his hard work and making sure that I always felt at home no matter where we were at, Leiden, Toulouse, or Kourou. Likewise, Alex Kinnard and Viyas Gupta for allowing me to do laundry at your houses and, again, making me feel at home the entire time I was in The Netherlands.

Lastly, I would like to thank Pablo Gallego for supporting this mission and for documenting everything that happened in French Guiana with his little orange camera! 


\section{TABLE OF CONTENTS}

Page

LIST OF TABLES x

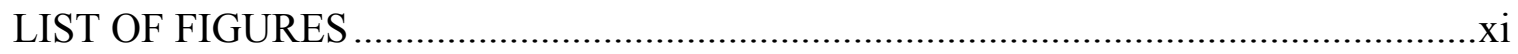

\section{CHAPTER}

1. INTRODUCTION.

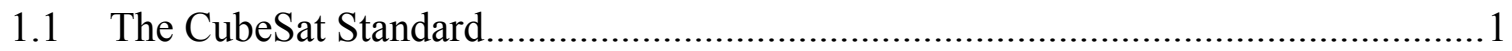

1.2 The Poly-Picosatellite Orbital Deployer ...........................................................2

1.3 History of Launch Opportunities Up To $2007 \ldots \ldots \ldots \ldots \ldots \ldots \ldots \ldots \ldots \ldots \ldots \ldots \ldots \ldots \ldots \ldots \ldots \ldots \ldots \ldots \ldots . . .4$

1.3.1 CubeSat Launch Integrators Up to 2007 .....................................................6

2. VEGA MAIDEN FLIGHT LAUNCH OPPORTUNITY …………..........................

2.1 ESA Recognizes CubeSats Have Limited Access to Space .......................................

2.2 The Vega Launch Vehicle ................................................................................. 10

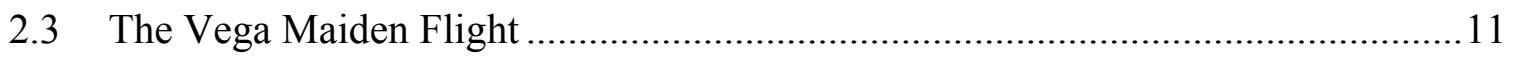

2.3.1 Selecting the CubeSats for The Vega Maiden Flight ........................................12

2.3.2 Selecting a CubeSat Integrator and Dispenser ................................................. 14

3. CUBESATS ON VEGA MAIDEN FLIGHT PROGRAM FLOW ............................16 


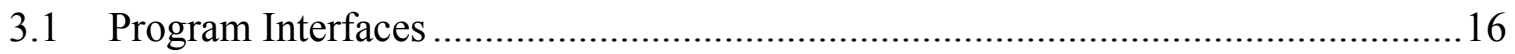

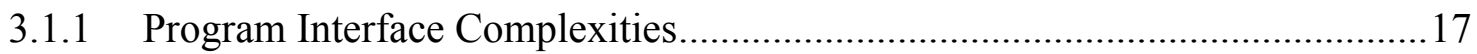

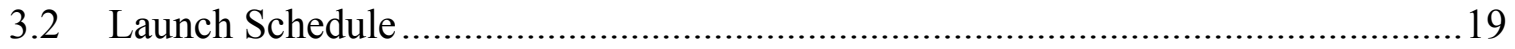

3.2.1 CubeSat Manifest Complications Due to Launch Delays ................................21

4. INTERFACE CONTROL REQUIREMENTS DEVELOPMENT ……………........25

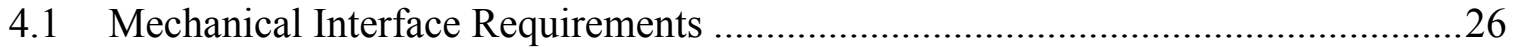

4.1.1 Mechanical Interface Requirements Development ........................................26

4.1.2 Resolution for P-POD Mechanical Interface Requirements Change ................28

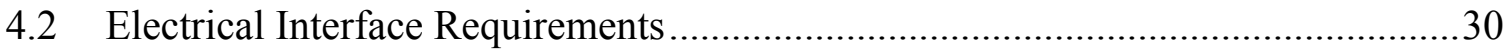

4.2.1 Electrical Interface Requirements Development.............................................30

4.2.2 Resolution for P-POD Electrical Interface Requirements Change ....................32

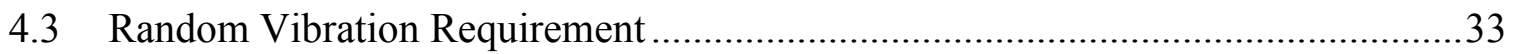

4.3.1 Random Vibration Requirement Development.................................................33

4.3.2 Resolution for The Change to The Random Vibration Requirement.................34

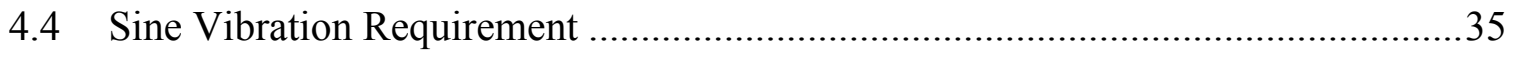

4.4.1 Sine Vibration Requirement Development ....................................................35

4.4.2 Resolution for The Change to The Sine Vibration Requirement .......................35

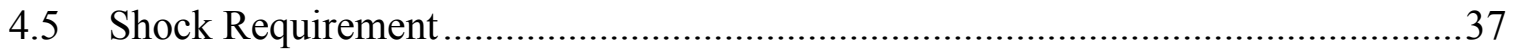

4.5.1 Shock Requirement Development..............................................................

4.5.2 Resolution for The Change to The Shock Requirement …...............................38 


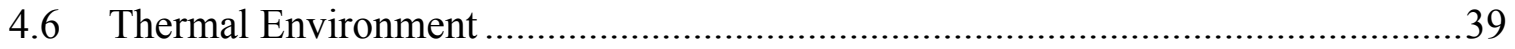

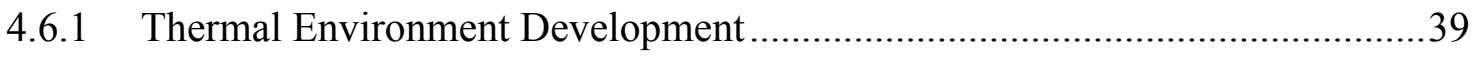

4.6.2 Resolution for The Change to The Thermal Environment..............................41

5. SYSTEM LEVEL ENVIRONMENTAL TESTING .............................................45

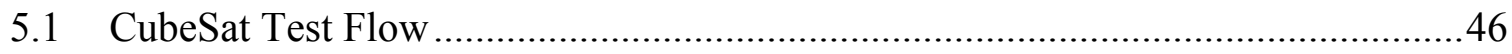

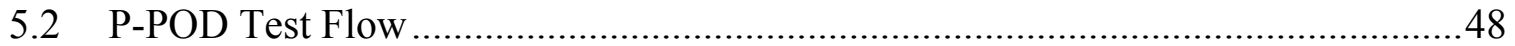

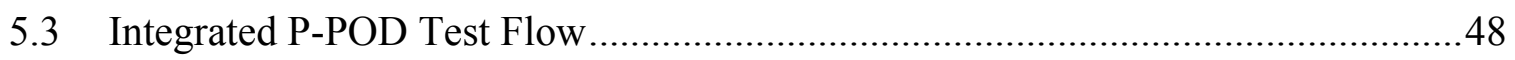

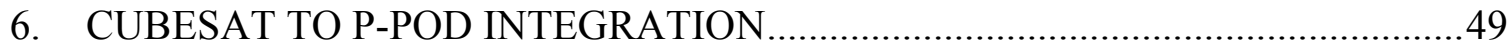

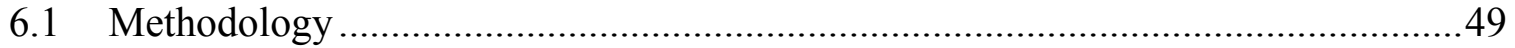

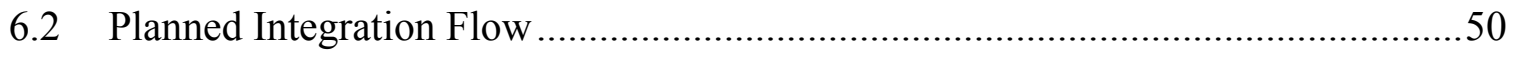

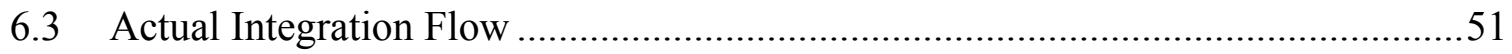

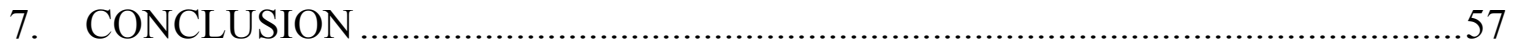

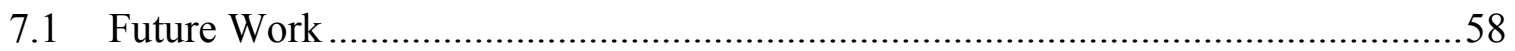

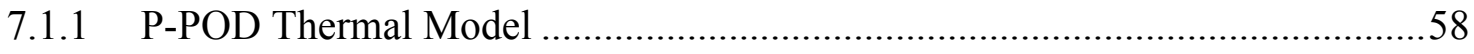

7.1.2 Cal Poly Team with a European Entity ......................................................59

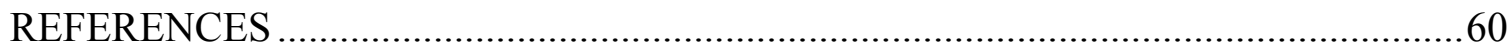


APPENDICES

APPENDIX A: PLANNED INTEGRATION SCHEDULE FOR THE CUBESATS

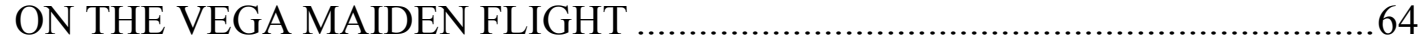

APPENDIX B: ACTUAL INTEGRATION SCHEDULE FOR THE CUBESATS

ON THE VEGA MAIDEN FLIGHT .65 


\section{LIST OF TABLES}

Table

Page

Table 1: List of CubeSats Launched from 2003 to 2007 ...............................................

Table 2: Final CubeSat Manifest for The Vega Maiden Flight ......................................24 


\section{LIST OF FIGURES}

Figure

Figure 1: MaSat-1 CubeSat developed by the Technical University of Budapest .............1

Figure 2: P-POD Mk. III Developed by Cal Poly ...................................................4

Figure 3: Number of CubeSats That Made It to Orbit per Year from 2003 to 2007 ..........6

Figure 4: University of Toronto's X-POD ...............................................................

Figure 5: AAUSat-4 Team Members Perform Diagnostics, Battery Charging, and Inspections on their CubeSat Post Vibration Testing Inside of the P-POD ............... 8

Figure 6: Vega Launch Vehicle Expanded View ......................................................10

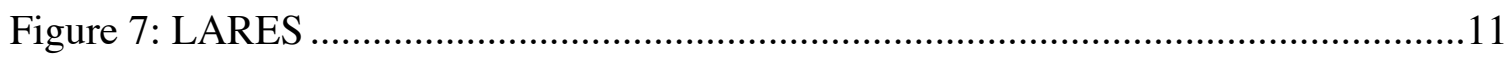

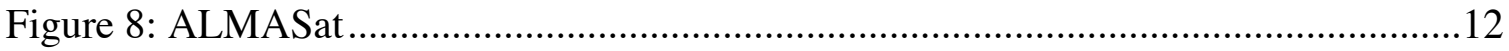

Figure 9: Payload Arrangement for The Vega Maiden Flight ......................................15

Figure 10: CubeSats on The Vega Maiden Flight Program Interfaces ...........................16

Figure 11: Standard Programmatic Interfaces When Cal Poly Performs the Role of

CubeSat Integrator

Figure 12: LARES, ALMASat, and 2 P-POD Mass Models Shown Post LARES

Support System Transportation to The Launch Site ..............................................22

Figure 13: Mk. III P-POD Coordinate System ..........................................................26

Figure 14: P-POD Mounting Configuration from the March 2009 P-POD to LSS IRS ...27

Figure 15: P-POD Mounting Configuration from the December 2009 P-POD to

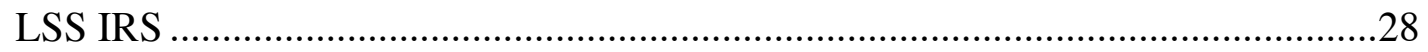

Figure 16: P-POD Electrical Interface Configuration from The March 2009 IRS ...........31

Figure 17: P-POD Electrical Interface Configuration from The December 2009 IRS .....32 
Figure 18: LARES with an Engineering Unit P-POD on the LSS for

Figure 19: Shock Spectrum for Equipment Qualification From ECSS-E-10-03A

Figure 20: LSS Thermal Model with P-PODs

Figure 21: P-POD Wall Temperatures Without Uncertainty Factors Applied.

Figure 22: P-POD Wall Temperatures with Thermal Washers and Without

Uncertainty Factors Applied.

Figure 23: P-POD Wall Temperatures with Surface Coatings and Thermal Washers and Without Uncertainty Factors Applied

Figure 24: P-POD and CubeSat Test Flow for The Vega Maiden Flight .46

Figure 25: Cal Poly 3U TestPOD on a Vibration Table.

Figure 26: The XaTcobeo, e-st@r, and Goliat CubeSats with The Flight P-POD just before integration with members from their teams, the ESA Education Office and Cal Poly .52

Figure 27: A Cal Poly Student Integrates MaSat-1 Into the Flight P-POD. .53

Figure 28: A Cal Poly Staff Member a UniCubeSat-GG Team Member Integrate UniCubeSat-GG into The P-POD .54

Figure 29: One of the Flight P-PODs Being Integrated to the LSS Platform by a

Cal Poly Staff Member and an ASI Technician .55

Figure 30: Two P-PODs with Thermal Tape on the LSS Just Prior to Fairing

Encapsulation .56

Figure 31: Picture of the Vega Maiden Flight Liftoff .57 


\section{INTRODUCTION}

\subsection{The CubeSat Standard}

The CubeSat Standard was developed in 1999 through collaboration between Professor Jordi Puig-Suari of California Polytechnic State University, San Luis Obispo (Cal Poly) and Professor Bob Twiggs of Stanford University [1]. This standard requires that the satellites are $10 \mathrm{~cm}$ cubes with a mass of less than $1 \mathrm{~kg}$, and that they are powered off while integrated on the launch vehicle. An example of a $1 \mathrm{U}$ CubeSat is shown in Figure 1 [2]. The original vision of the CubeSat Standard was to provide a lowcost platform, which could be rapidly developed to train university students to design, manufacture, test, and operate satellites within the timeline of a student's academic career. Since the CubeSat Standard's inception, it has become recognized worldwide and is currently being utilized by hundreds of universities, government organizations, and private companies.

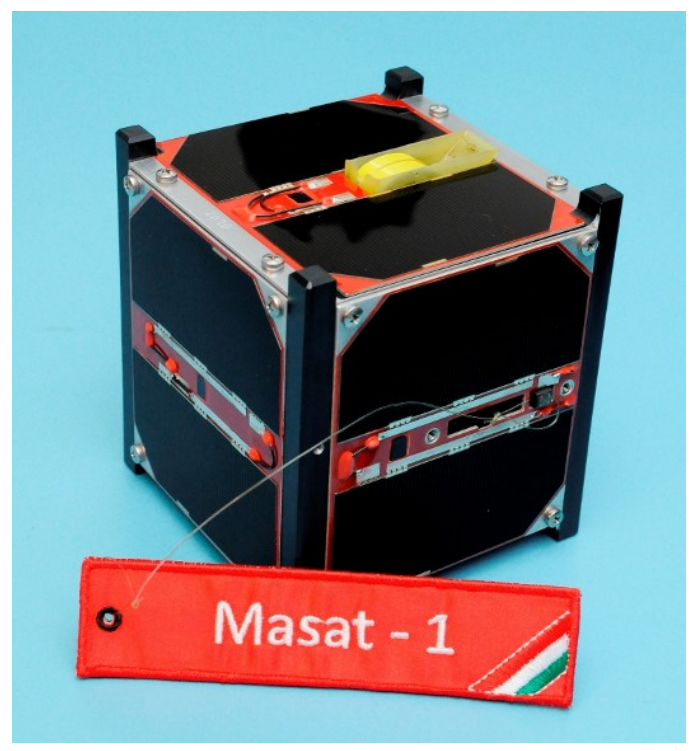

Figure 1: MaSat-1 CubeSat developed by the Technical University of Budapest 


\subsection{The Poly-Picosatellite Orbital Deployer}

The Poly-Picosatellite Orbital Deployer (P-POD), shown in Figure 2, was designed to be a safe and reliable method to deploy CubeSats from a launch vehicle. The driving requirements for the design of the P-POD were the safety of the launch vehicle and other satellites, simple interface, compatibility with the CubeSat Standard, and mass optimization. The overall size and design of the P-POD makes its place on a launch vehicle extremely versatile. The following design decisions were implemented to meet these requirements [3].

- Enclosed Aluminum Structure: The enclosed structure protects the launch vehicle and other satellites from any CubeSat structural failures, and serves as a faraday cage to protect the launch vehicle from any accidental radio transmissions from the CubeSats.

- Space-Qualified Door Release Mechanism: The release mechanism for the PPOD door is a critical area of concern, not only for mission success of CubeSats, but also for the safety of the launch vehicle and other satellites. This single point of failure is reduced greatly by using mechanisms with significant flight heritage and built-in redundancy.

- Standard Interface to the Launch Vehicle: Six bolts are used to interface with the launch vehicle. These bolts can vary in size and location on the P-POD, increasing the flexibility in mounting configurations. A simple interface reduces the time needed for safety analysis and designing complex adapters for a launch vehicle. 
- Smooth Internal Surface: The interior of the P-POD is flat and smooth, this reduces the probability of a CubeSat seizing onto an interior protrusion.

- Testing of P-POD Engineering Units: P-POD Engineering units are tested to qualification levels for every new flight on a launch vehicle. P-POD Engineering units are identical to Flight P-POD units, and are not considered for flight status due to the amount of testing that is performed on those units.

- Testing of Integrated P-POD Flight Units: The Flight P-PODs follow a test plan specific to each mission, which consists of testing pre- and post-CubeSat integration. Prior to the flight CubeSat being integrated into a P-POD, it will undergo vibration and thermal vacuum testing per launch vehicle requirements. Then, after the flight CubeSat is integrated into a P-POD, the integrated system will undergo one last vibration test, so the launch vehicle provider can be assured that the integrated system can safely survive the launch environment.

- Contain More than One Satellite: The design choice to hold more than one 1U CubeSat came from the desire to reduce the launch cost of a CubeSat by having up to three $1 \mathrm{U}$ CubeSats share a launch adapter. 


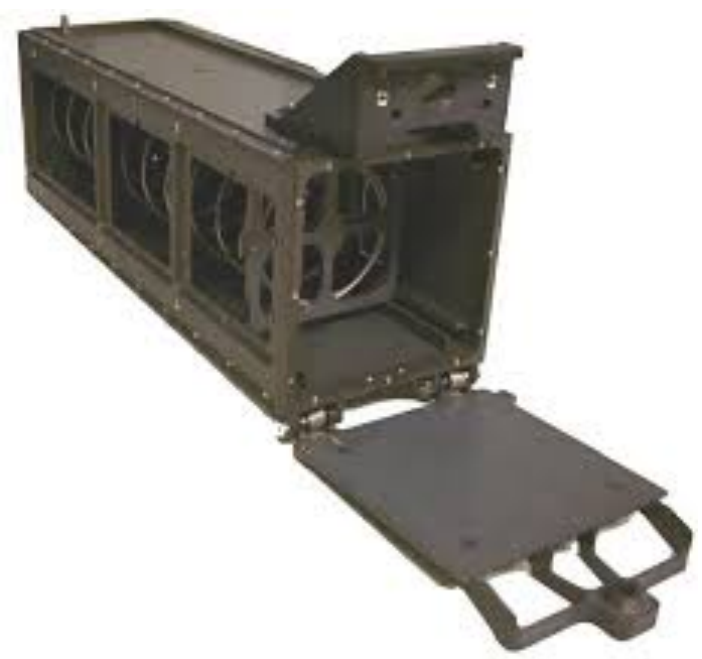

Figure 2: P-POD Mk. III Developed by Cal Poly

\subsection{History of Launch Opportunities Up To 2007}

For large satellite programs, such as GPS or DirecTV, there are a variety of launch opportunities. However, it is more difficult for CubeSat programs to get launch opportunities due to limited funding and inexperience in coordinating the launches. In order for CubeSats to get launch opportunities, it is much simpler if they aggregate and share the overhead costs associated with a given launch opportunity. A launch integrator who can group many satellites to rideshare on an existing launch opportunity can help accomplish this task. The first launch of CubeSats did not take place until 2003. Between 2003 and 2007 there were only six launch opportunities for CubeSats, one of which was a launch failure and two that only allowed satellites fly that were developed in the same country as the launch vehicle. The CubeSats that were integrated to launch vehicles between 2003 and 2007 are listed in Table 1, and the number of CubeSats that made it to orbit per year is illustrated in Figure 3 [4]. 
Table 1: List of CubeSats Launched from 2003 to 2007

\begin{tabular}{|c|c|}
\hline CanX-1 & University of Toronto (UTIAS) \\
\hline DTUsat & Technical University of Denmark \\
\hline CUTE-1 & Tokyo Institute of Technology \\
\hline CubeSat XI-IV & University of Tokyo \\
\hline AAU CubeSat & Aalborg University \\
\hline QuakeSat & Stanford University \\
\hline \multicolumn{2}{|c|}{ October 27, 2005 - Kosmos-3M - SSETI Express } \\
\hline UWE-1 & University of Wurzburg \\
\hline CubeSat XI-V & University of Tokyo \\
\hline Ncube-2 & Norwegian Universities \\
\hline \multicolumn{2}{|c|}{ February 21, 2006 - M-V-8 - ASTRO-F } \\
\hline Cute 1.7 & Tokyo Institute of Technology \\
\hline \multicolumn{2}{|c|}{ July 26, 2006 - Dnepr - Belka (Launch Failure) } \\
\hline SACRED & University of Arizona \\
\hline ION & University of Illinois \\
\hline Rincon 1 & University of Arizona \\
\hline ICE Cube 1 & Cornell University \\
\hline KUTESat & University of Kansas \\
\hline NCUBE-1 & Andoya Rocket Range / Norwegian Space Centre \\
\hline HAUSAT-1 & Hankuk Aviation University \\
\hline SEEDS-1 & Nihon University \\
\hline $\mathrm{CP}-2$ & Cal Poly, San Luis Obispo \\
\hline AeroCube 1 & Aerospace Corporation \\
\hline MEROPE & Montana State University \\
\hline HeaHuak'i & University of Hawaii \\
\hline ICE Cube 2 & Cornell University \\
\hline $\mathrm{CP}-1$ & Cal Poly, San Luis Obispo \\
\hline \multicolumn{2}{|c|}{ December 16, 2006 - Minotaur I - TacSat-2 } \\
\hline GeneSat-1 & NASA Ames / Santa Clara University \\
\hline \multicolumn{2}{|c|}{ April 17, 2007 - Dnepr - EgyptSat } \\
\hline CSTB1 & Boeing \\
\hline AeroCube 2 & Aerospace Corporation \\
\hline $\mathrm{CP}-4$ & Cal Poly, San Luis Obispo \\
\hline Libertad-1 & Sergio Arboleda University \\
\hline CAPE-1 & University of Louisiana at Lafayette \\
\hline $\mathrm{CP}-3$ & Cal Poly, San Luis Obispo \\
\hline MAST & Tethers Unlimited \\
\hline
\end{tabular}




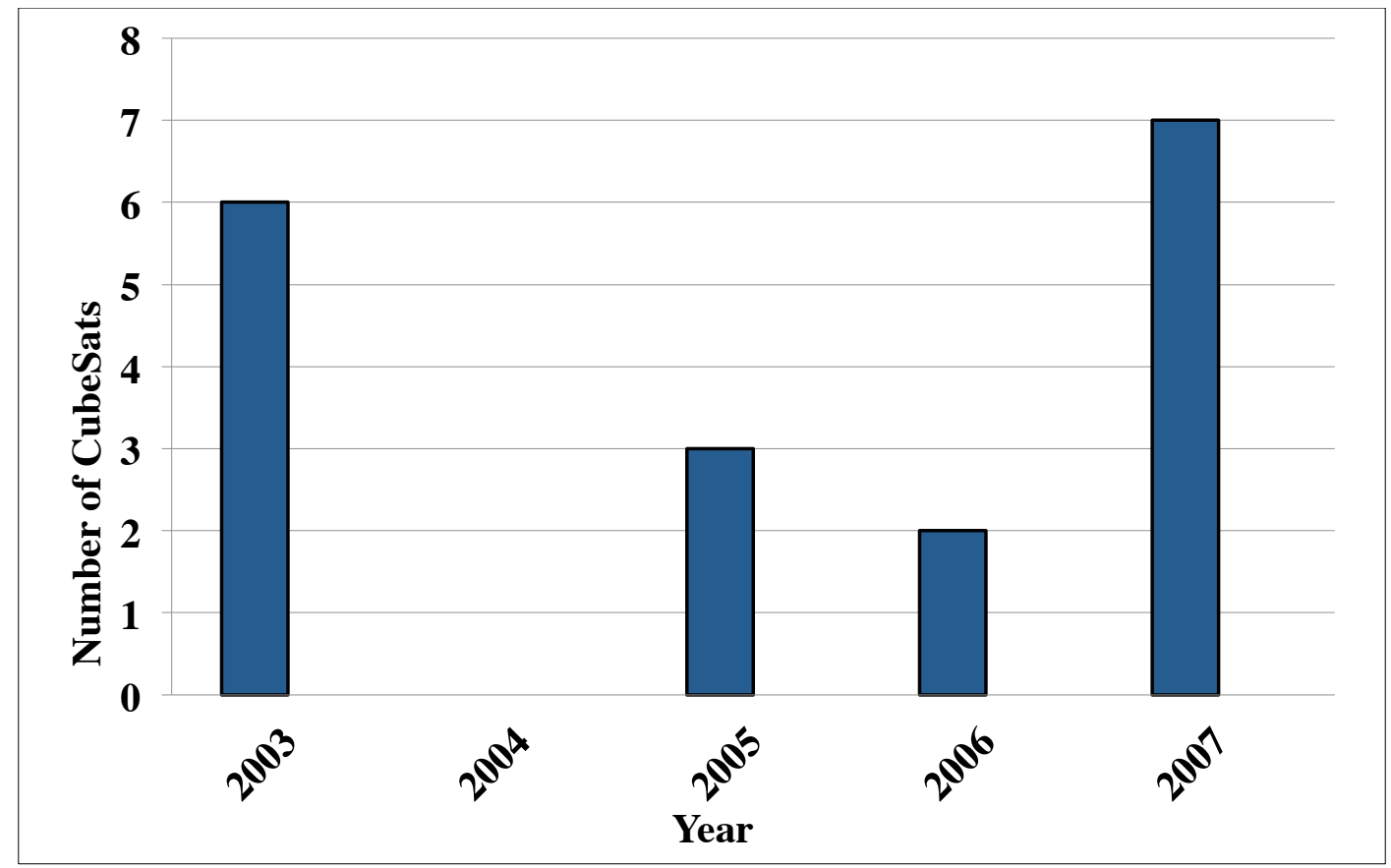

Figure 3: Number of CubeSats That Made It to Orbit per Year from 2003 to 2007

\subsubsection{CubeSat Launch Integrators Up to 2007}

In 2007, there were not many small satellite launch integrators, let alone CubeSat launch integrators. Up until this point, only two organizations-Cal Poly and The University of Toronto Institute for Aerospace Studies (UTIAS)—-had CubeSat dispenser hardware with flight heritage. These two organizations were also the only ones with experience performing CubeSat-to-dispenser integration and dispenser-to-launch vehicle integration. By 2007, UTIAS had performed CubeSat launch integration activities for one launch, and Cal Poly had performed the same activities for two launches and provided hardware and technical assistance on a third launch with CubeSats. Additionally, Cal Poly's P-POD had flown on three different missions, while the University of Toronto's CubeSat dispenser called the eXperimental Push Out Deployer (X-POD), shown in Figure 4, had only flown once [5]. 


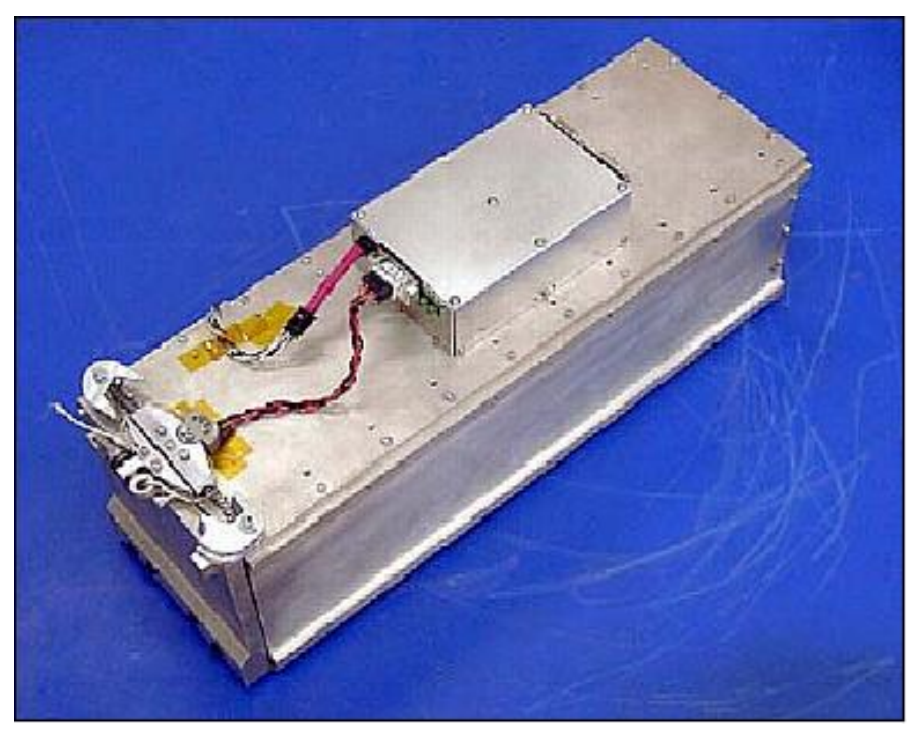

Figure 4: University of Toronto's X-POD

A major difference between the two CubeSat dispensers is that the P-POD has ports to access the CubeSat while it's integrated in the dispenser, whereas the X-POD does not have such a feature. The access port feature allows for the CubeSat to be inspected post-testing and after transportation between the CubeSat-to-dispenser integration facility and the dispenser-to-launch vehicle facility, an example of a CubeSat post-integration inspection is shown in Figure 5 [6]. The access port feature also allows for the CubeSats to be inspected without breaking the configuration of the P-POD's door release mechanism following final environmental testing. These features are beneficial to both the CubeSat developers and the launch vehicle providers. 


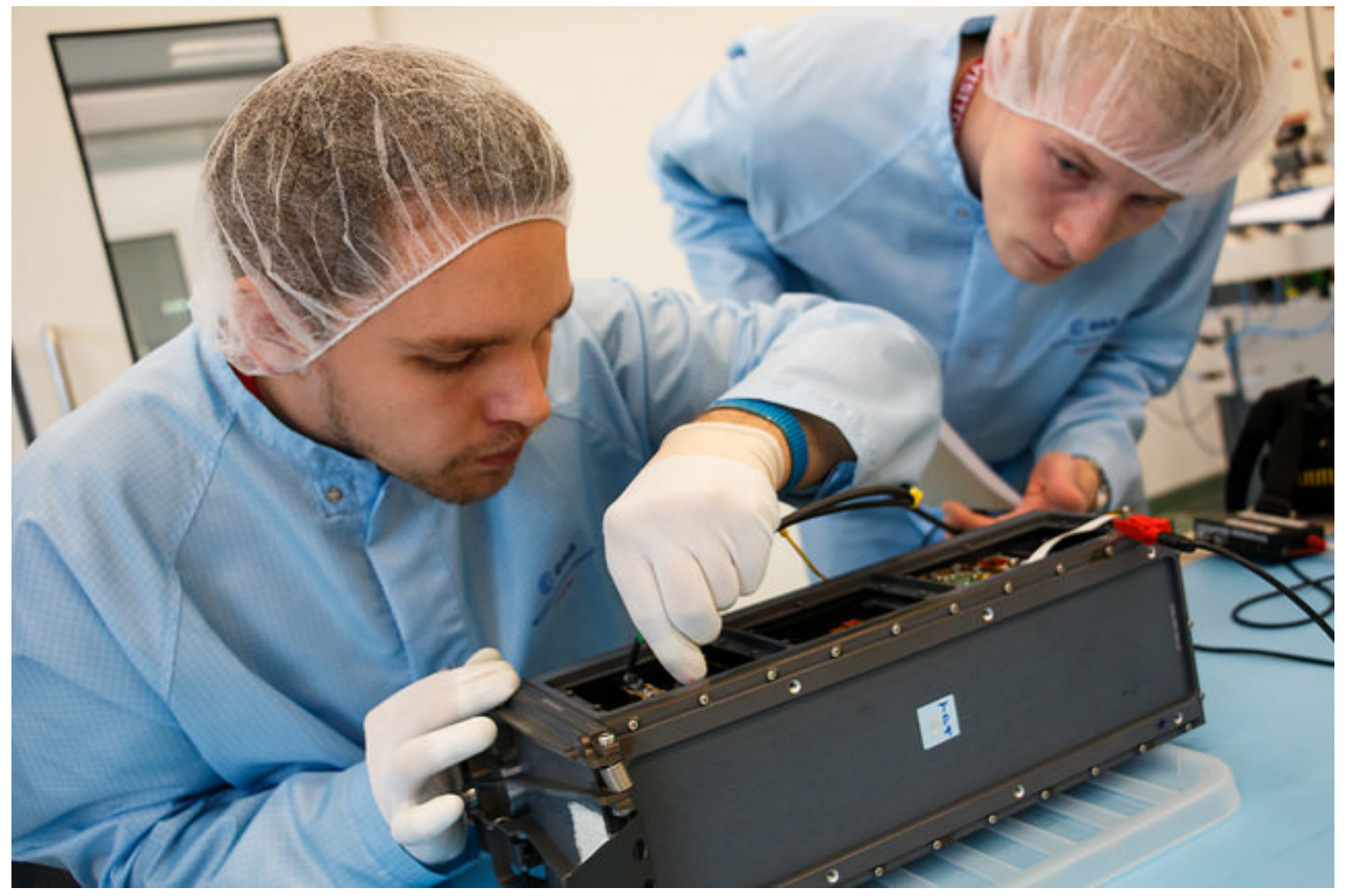

Figure 5: AAUSat-4 Team Members Perform Diagnostics, Battery Charging, and Inspections on their CubeSat Post Vibration Testing Inside of the P-POD 


\section{VEGA MAIDEN FLIGHT LAUNCH OPPORTUNITY}

\subsection{ESA Recognizes CubeSats Have Limited Access to Space}

In early 2007, Cal Poly started working with the Education Office in the European Space Agency (ESA) on a project called the Global Educational Network for Satellite Operations (GENSO). The purpose of GENSO was to create a worldwide network of ground stations which spacecraft operators could use to uplink commands and download data [7]. GENSO's goals were to increase the data return from educational space missions and change the way that these missions are managed, dramatically increasing the level of access to the educational spacecraft. At this time, the development of CubeSats by universities was gathering a lot of momentum, and with their limited power, data rates, and short design life at the time - typically 1 to 6 months — it was thought that CubeSats would be one of the prime beneficiaries of GENSO.

Early in the development of GENSO, the Education Office at ESA noticed that most of the academic collaborators were developing CubeSats without any launch opportunities. The ESA Education Office quickly realized they would have a ground station network set up for CubeSats to use, but little-to-no CubeSats to use it. As a result, the Education Office started discussions with ESA's Directorate of Launchers, ESA's program directorate for procuring launches [8], to find a way to get a launch opportunity for university CubeSats developed by ESA member and cooperating states. At this point, the Directorate of Launchers identified the maiden Flight of the Vega launch vehicle, which was still in development at the time, as potential launch. On May 28, 2007, the ESA Education Office and the Directorate of Launchers signed an agreement to fly an 
educational payload on the Vega Maiden Flight, which was scheduled to launch in September 2008 [9]. This normally would have been an ambitious schedule to fly CubeSats on an ESA launch vehicle for the first time, but it was well known that the development of the Vega launch vehicle was behind schedule and that a launch delay was very probable.

\subsection{The Vega Launch Vehicle}

The Vega launch vehicle is an expendable launch system in use by Arianespace, and was jointly developed by the Italian Space Agency and the European Space Agency. The development of the Vega launch vehicle began in 1998 with the goal of being able to put small payloads, 300 to 2,500 $\mathrm{kg}$ satellites, into low earth orbit. Vega is composed of three Solid Rocket Motor (SRM) stages and a restartable liquid-propellant fourth stage referred to as the Attitude Vernier Upper Module (AVUM), shown in Figure 6 [10]. The Vega launch vehicle stands approximately $30 \mathrm{~m}$ tall, and launches from the Guiana Space Centre in Kourou, French Guiana.

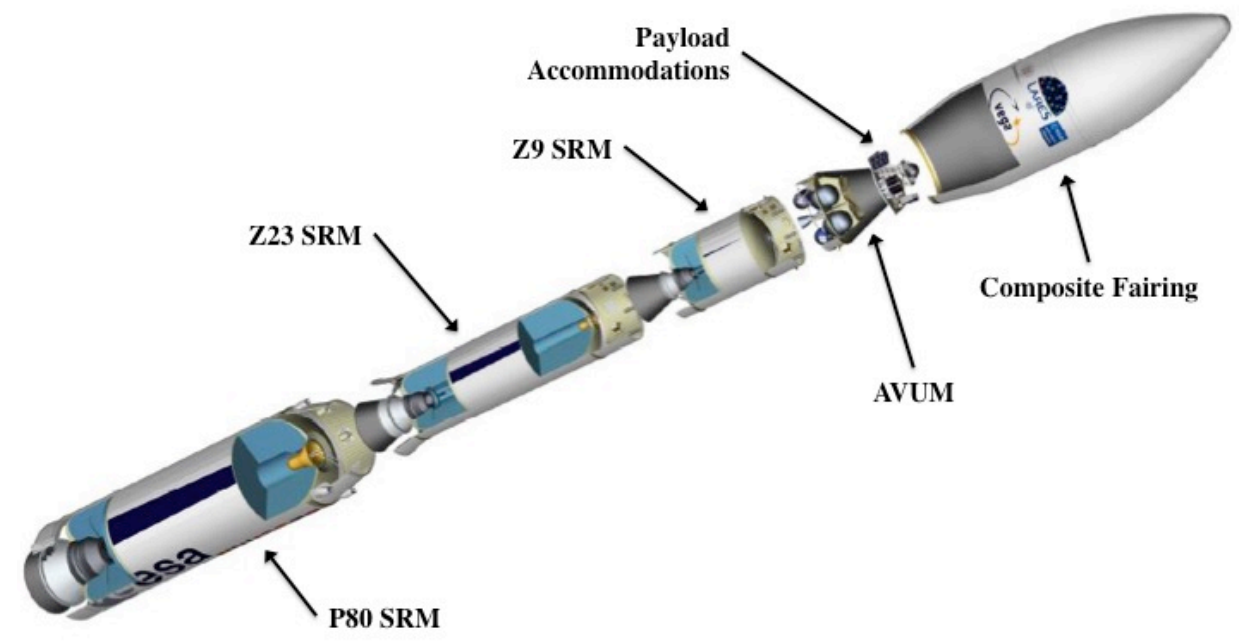

Figure 6: Vega Launch Vehicle Expanded View 


\subsection{The Vega Maiden Flight}

The first flight of the Vega launch vehicle was designed to be a qualification flight for the launch vehicle to determine it's performance and record measurements of the dynamic and thermal environments for analysis for future launches. However, ASI and ESA recognized the unused margin for this launch, and decided that both organizations had satellite programs that were willing to take the risk of the first flight of a launch vehicle in order to get, essentially, a free launch.

The primary payload for the Vega Maiden Flight was to be the Laser Relativity Satellite (LARES) sponsored by ASI, shown Figure 7 [11]. LARES is a passive satellite with the scientific objective to test the prediction of the Lense-Thirring Effect from Einstein's theory of General Relativity. LARES is a $364 \mathrm{~mm}$ sphere made of a tungsten alloy, with a mass of approximately $400 \mathrm{~kg}$ and 92 corner cube reflectors spread across its surface. LARES was injected into a $1450 \mathrm{~km}$ circular orbit with an inclination of 69.5 degrees.

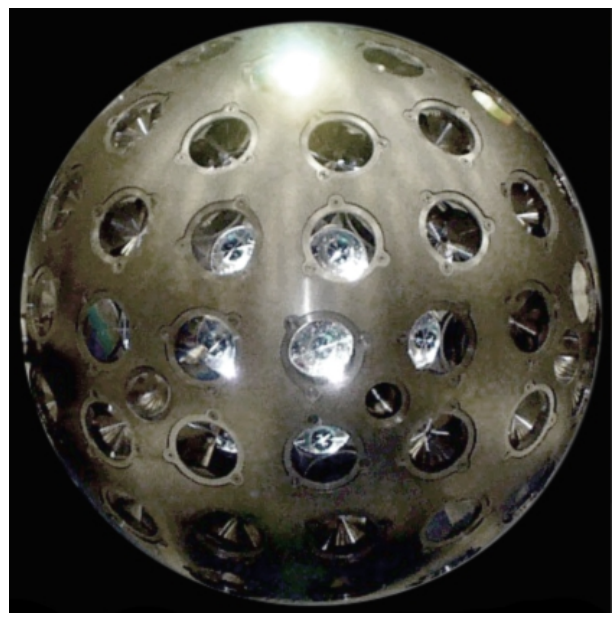

Figure 7: LARES 
The other secondary or auxiliary payloads on the Vega maiden flight were the three P-PODs and CubeSats sponsored by the ESA Education Office, and ALMASat (Alma Mater Satellite), which was sponsored by ASI. ALMASat was developed by the University of Bologna, and is pictured in Figure 8 [12]. ALMASat has a mass of approximately $12 \mathrm{~kg}$ and is cube-shaped with dimensions of $300 \mathrm{~mm}$ on all sides. ALMASat's mission was to create a low-cost and reliable spacecraft bus that could accommodate payloads with different power and volume requirements. ALMASat was to be injected into the upper stage's disposal orbit, which was approximately $350 \mathrm{~km} \mathrm{x}$ $1450 \mathrm{~km}$ with an inclination of 69.5 degrees.

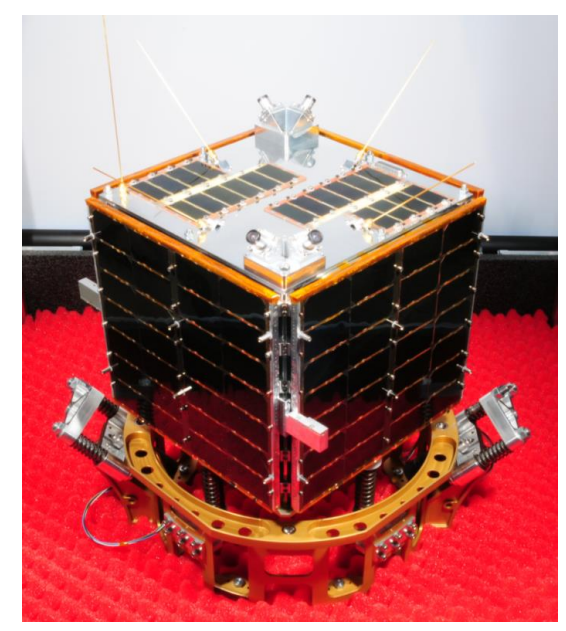

Figure 8: ALMASat

\subsubsection{Selecting the CubeSats for The Vega Maiden Flight}

After the ESA Education Office and the Directorate of Launchers signed an agreement to launch an educational payload on the Vega Maiden Flight, an Announcement of Opportunity was released in October of 2007 to let CubeSat developers at universities in ESA member and cooperating states know there would be a chance for a free launch. In February of 2008, a call for proposals went out notifying these CubeSat 
developers of a free launch opportunity on the Vega Maiden Flight for the end of 2008 or early 2009. The call was only for $1 \mathrm{U}$ CubeSats, and it was ESA's original intention to select six CubeSats for flight, as well as two back-ups. The selection of CubeSats was made in April 2008, and since ESA received more proposals than originally anticipated22-the ESA Education Office decided to select nine CubeSats for launch with two backups listed below [13]. Out of the CubeSats selected, PW-Sat and Goliat would be the first satellites launched for Poland and Romania, respectively.

- Goliat: Developed by the University of Bucharest, Goliat was designed to image the surface of the Earth using a digital camera and perform in-situ radiation dose and micrometeoroid flux measurements.

- PW-Sat: Developed by Warsaw University of Technology, PW-Sat was designed to test a deployable atmospheric drag device for de-orbiting CubeSats.

- e-st@r: Developed by Politecnico di Torino, e-st@r was designed to demonstrate an active 3-axis attitude determination and control system, including an inertial measurement unit.

- XaTcobeo: Developed by the University of Vigo, XaTcobeo was designed to demonstrate a software-defined radio and solar panel deployment mechanism.

- Robusta: Developed by the University of Montpellier, Robusta was designed to test and evaluate radiation effect on bipolar transistor electronics components. 
- UniCubeSat-GG: Developed by the University of Rome, La Sapienza, UniCubeSat-GG was designed to perform in-situ measurements of atmospheric neutral density using a Broglio drag balance instrument.

- AtmoCube: Developed by the University of Trieste, AtmoCube was designed to perform in-situ monitoring of space environment parameters such as radiation flux, magnetic field, and atmospheric density.

- OUFTI-1: Developed by the University of Liège, OUTI-1 was designed to test the use of the D-STAR amateur radio digital communication protocol in space.

- UWE-3: Developed by the University of Würzburg, UWE-3 was designed to demonstrate an active 3-axis attitude determination and control system using magnetorquers.

- HiNCube: Developed by Narvik University College, HiNCube was selected to be a back up on the Vega Maiden Flight. The mission of HiNCube was to image the Earth's surface using a digital camera.

- SwissCube-2: Developed by École Polytechnique Fédérale de Lausanne, SwissCube-2 was selected to be a back up on the Vega Maiden Flight. The mission of SwissCube-2 was to characterize the airglow phenomenon in the Earth's atmosphere.

\subsubsection{Selecting a CubeSat Integrator and Dispenser}

As discussed earlier, in 2007 there were only two commercially available CubeSat dispensers, the P-POD and the X-POD, and each dispenser had its own integrator, $\mathrm{Cal}$ 
Poly and the University of Toronto, respectively. As ESA defined its requirements for a CubeSat dispenser, it determined that the dispenser, integrated with the CubeSats, would have to be transported for vibration testing and delivery to the launch site, and that they would want to verify that the CubeSats successfully survived each trip. Also, since this was the first flight of the Vega launch vehicle, there was a possibility that the launch would be delayed after the P-PODs had been integrated on the launch vehicle and encapsulated inside the fairing, meaning there would be no access to the P-PODs or CubeSats. Consequently, ESA wanted the option to have the CubeSats charge their batteries as late as possible in the integration flow, this meant being able to charge while integrated in the CubeSat dispenser. Both of these requirements meant the P-POD was the only choice for the mission. In August of 2008, Cal Poly and ESA entered into an agreement for Cal Poly to deliver three P-PODs and provide CubeSat to P-POD and PPOD to launch vehicle integration services. The final arrangement of all of the payloads on the Vega Maiden Flight is shown in Figure 9 [14].

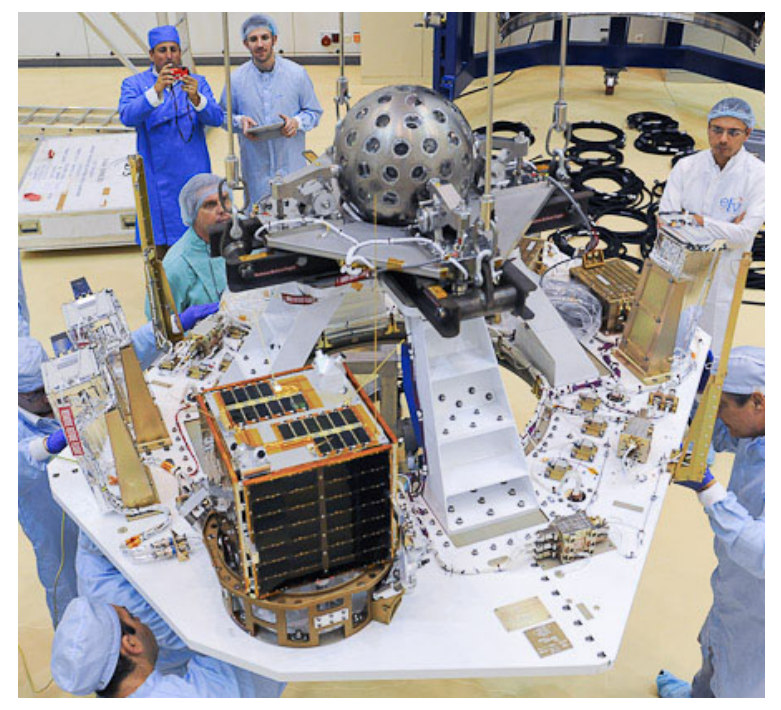

Figure 9: Payload Arrangement for The Vega Maiden Flight 


\section{CUBESATS ON VEGA MAIDEN FLIGHT PROGRAM FLOW}

\subsection{Program Interfaces}

For the Vega Maiden Flight, the ESA Education Office was responsible for all the efforts necessary to deliver the fully assembled, integrated, and tested P-PODs and CubeSats to the LARES team. This included all the analyses and documentation to complete interface verification efforts and range safety approvals. The analyses and documentation required inputs from Cal Poly and the CubeSat developers in order to be completed. The Education Office set up programmatic interfaces, shown in Figure 10, which has them at the center as the go-between for all of the organizations that were involved with the CubeSat effort on the Vega Maiden Flight [15].

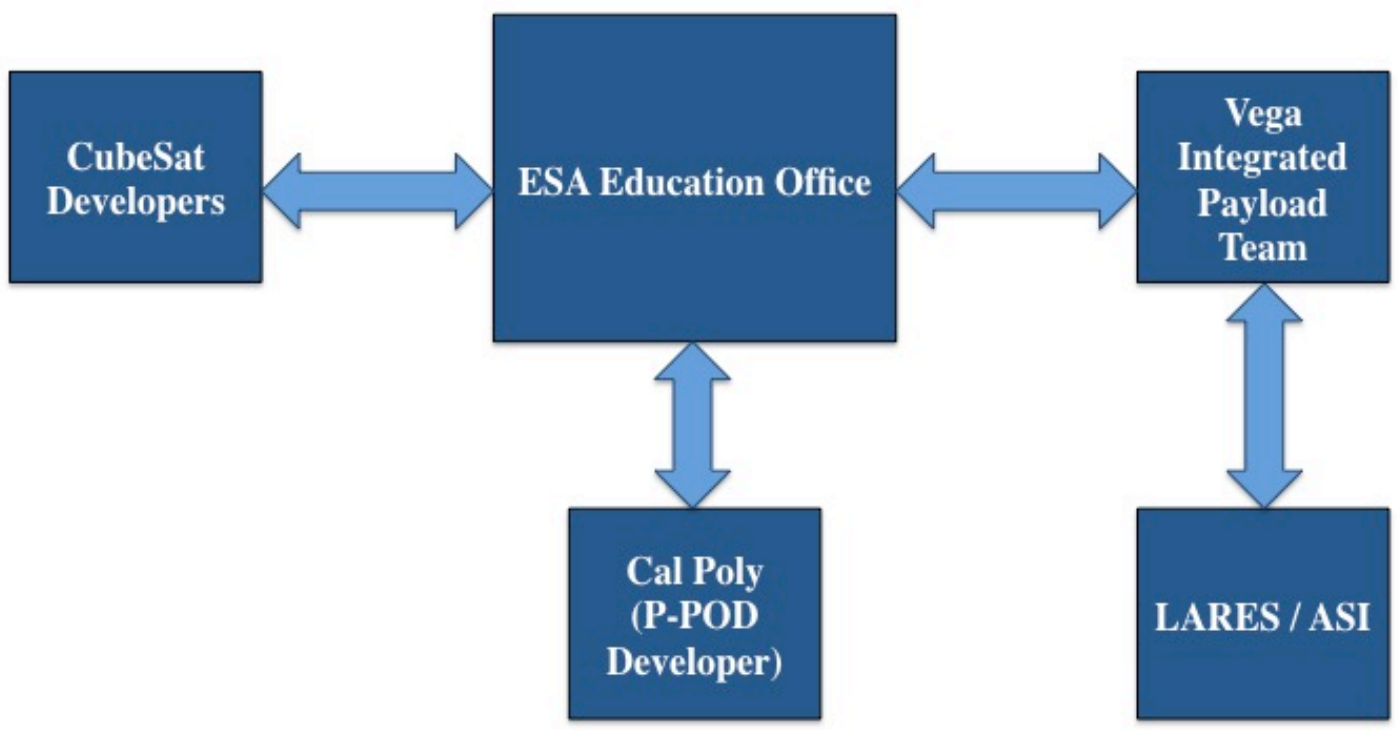

Figure 10: CubeSats on The Vega Maiden Flight Program Interfaces 


\subsubsection{Program Interface Complexities}

Typically, for a P-POD launch, Cal Poly not only provides the P-POD and performs the CubeSat integration into the P-POD; it also assumes the CubeSat integrator role that the ESA Education Office performed for this mission. The CubeSat integrator role involves controlling the requirements flow and ensuring the CubeSat teams can meet technical and schedule requirements, a flow chart of the programmatic interfaces for this type of mission is shown in Figure 11. This role can be very time-intensive, and because all of the other mission partners were based in Europe, it would have been very inefficient for Cal Poly to fulfill that role for this mission. However, not having direct lines of communication to the CubeSat teams or launch vehicle interface created some issues that made it harder to complete tasks.

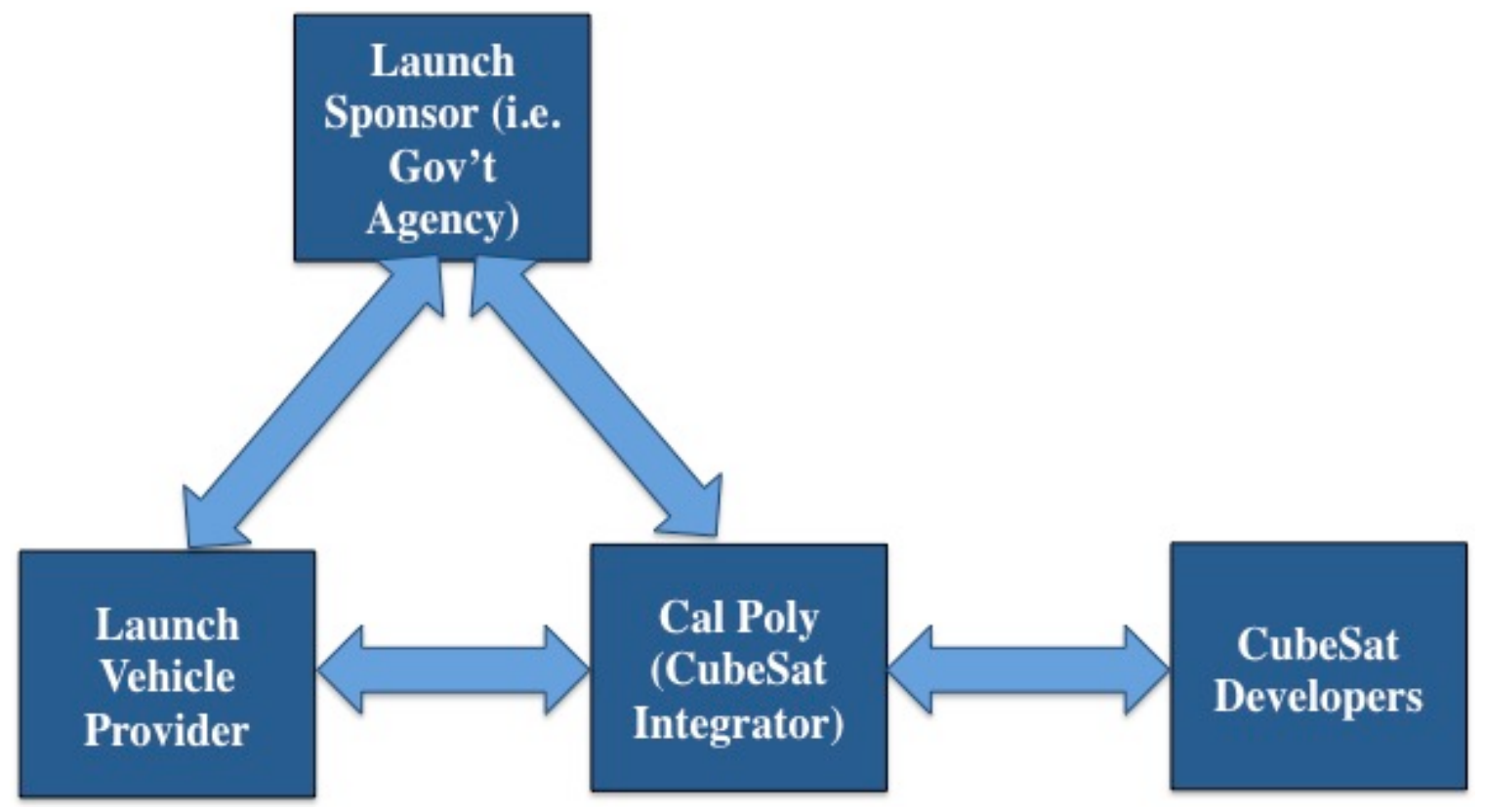

Figure 11: Standard Programmatic Interfaces When Cal Poly Performs the Role of CubeSat Integrator 
The first challenge was the timeliness of the exchange of information between parties. If the launch vehicle or CubeSat teams had a question for Cal Poly, it would usually take 2-3 days for the questions to be answered, and the same was true when Cal Poly had questions. Given the eight-hour time difference between Cal Poly and Central Europe, the end of ESA's workday was the beginning of Cal Poly's workday. Almost every phone call had to be pre-coordinated at least 1-2 days in advance. If the Vega Maiden Flight launched on its original date, this method of sharing information would have made completing the mission very challenging, but with all of the launch delays, this did not cause many issues.

Due to the launch delays, there were opportunities to have two face-to-face meetings with the ESA Education Office, the CubeSat teams, and Cal Poly. These meetings were referred to as workshops, and were held at the European Space Research and Technology Centre (ESTEC) in The Netherlands. The first workshop was on January 20-22, 2009, and while it was open to CubeSat teams from all over the world, it was required for the CubeSat teams selected for the Vega Maiden Flight to present their current status. The first ESA CubeSat Workshop had over 200 participants representing universities from all over the world [16]. The second workshop was held on April 7-9, 2010 and was limited to only the ESA Education Office, the CubeSat teams on the Vega Maiden Flight, and Cal Poly. This workshop, again, required each CubeSat team to present their current status, while the other presentations were from the ESA Education Office and other ESA employees regarding how requirements would be verified.

Another challenging aspect of this effort was that Cal Poly was not part of the flow of requirements to the CubeSat to P-POD Interface Control Document (ICD). 
Typically, the CubeSat teams have an ICD, which contains all of the requirements they need to verify in order to fit inside the P-POD and be certified for launch. The requirements come from three primary sources: the CubeSat Design Specification, the PPOD to launch vehicle ICD, and range safety. In the P-POD to Launch Vehicle ICD, there are a handful of requirements that must be flown down to the CubeSat teams, but the majority are satisfied at the P-POD level. For this mission, there were several requirements that were flown down to the CubeSat level that should have remained at the P-POD level for verification. One such requirement was for the integrated P-POD's first fundamental mode to be above a certain frequency, and it is usually verified through analysis and then checked during vibration testing. This requirement was flowed down to the CubeSat teams; however, this requirement is used as an input to the launch vehicle's coupled load analysis, and only needs to be verified at the integrated system level, not the CubeSat level. Additionally, this analysis is usually difficult for CubeSat teams to accomplish since they usually have low fidelity Computer Aided Drafting (CAD) models of their satellite. Even if the CubeSat team has the correct software and expertise to complete the modal analysis, it is nearly impossible to verify the finite element model via test because the CubeSats are usually covered in solar cells and there is no place to mount an accelerometer to measure the CubeSat's response.

\subsection{Launch Schedule}

The Vega Maiden Flight saw many launch delays, but most of the delays did not come as a surprise since the Vega development schedule was public. It was easy to see early on that the milestones required for the first flight were not going to be completed on time. The initial launch delay was built in to the CubeSat Call for Proposals to fly on the 
Vega Maiden Flight when it was released at the beginning of 2008, when the launch date was in December of 2008; the call suggested that CubeSats that could also be ready in early 2009 should apply as well [9]. In the middle of 2008, when Cal Poly was already on contract, the launch date was expected to be no earlier than mid-2009. In early 2009, the launch date was postponed to late 2010, and then late 2011. At the end of 2010, the list of milestones that needed to occur for Vega to fly was dwindling and it was becoming less and less likely that there would be any more significant launch delays. Typically, if a CubeSat team finds out about a launch delay well in advance of the launch date, it's a welcome relief, but in this case there were three large launch slips, which led to some programmatic issues that would not have been encountered otherwise.

In mid-2011, the launch was scheduled for January 26, 2012 and the schedule was beginning to close. In early October the second and third stage motors, as well as the AVUM upper stage, were transported from Italy to the launch site [17]. With a launch date set, the ESA Education Office set a schedule for the delivery of the tested CubeSats and P-PODs and for the completion of the verification documents. The Education Office scheduled to have the P-PODs delivered to ESTEC the second week of October 2011 to complete the P-POD harnesses and to be inspected for compliance with documentation that was previously submitted. Then the CubeSats would be delivered the third week of October for inspections and integration into the P-PODs. The integrated P-POD would then be transported to Toulouse, France for final acceptance vibration testing in early November, then delivered to the launch site in French Guiana the last week of November for integration to the launch vehicle and launch. However, the launch experienced one 
last launch slip to February 13, 2012, which was unfortunately after the P-PODs integrated with the flight CubeSats were delivered to the launch site.

\subsubsection{CubeSat Manifest Complications Due to Launch Delays}

During a launch campaign, it is not uncommon for there to be launch delays, and the Vega Maiden Flight was no different. For the primary payload on a launch, if there is an issue encountered during development, integration, or testing, the launch date can be negotiated with the launch vehicle provider in order to come up with a new launch date that works for both parties to ensure mission success. However, for CubeSats on a rideshare mission, if the CubeSat encounters any issues the CubeSat team cannot negotiate a later launch date; the launch will happen with or without the CubeSats. The CubeSat team would need to manage their schedule delays by reducing the amount of margin in the schedule, or reducing the amount of mission assurance testing in order to meet the schedule. Furthermore, the CubeSat integrator would have contingency plans in case one or several of the CubeSats cannot make the schedule. In the case of the Vega Maiden Flight, it was determined that if one or two CubeSats could not meet the schedule, CubeSat mass models would be mechanically fixed to the P-POD, so that the flight CubeSats could be deployed, while the mass models would stay with the P-POD and not be ejected into space. If three of the CubeSats could not make the schedule, then a P-POD mass model would fly instead, an example of two P-POD mass models are shown in Figure 12 [18]. 


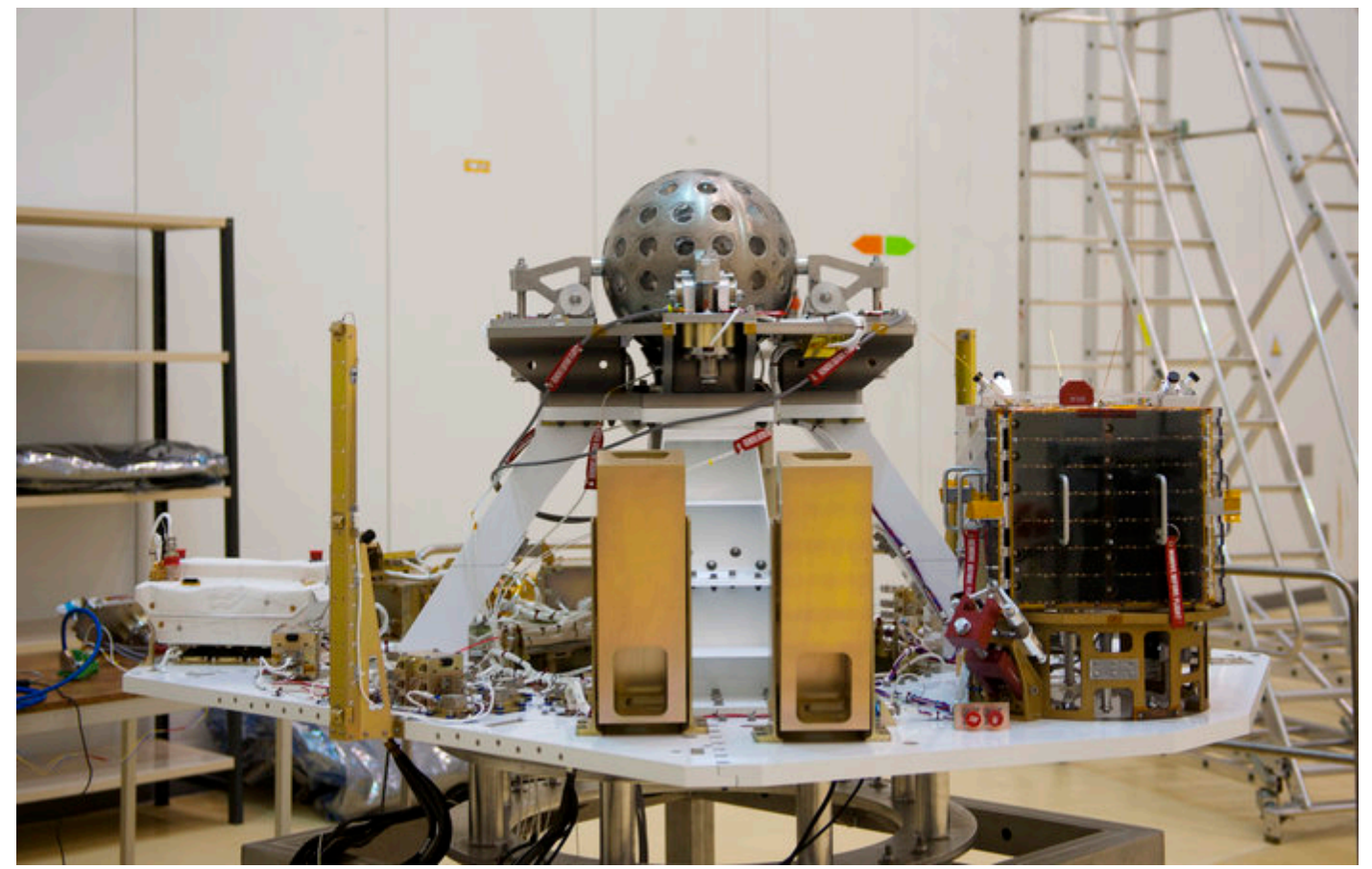

Figure 12: LARES, ALMASat, and 2 P-POD Mass Models Shown Post LARES Support System Transportation to The Launch Site

In the case of the Vega Maiden Flight, the three long launch delays caused some unique issues for the CubeSat teams: the desire to get on orbit in a timely manner, student turnover, and the availability of funding. Between 2008 and 2011, the market for CubeSat integrators started to take shape. There were two launch opportunities which European university CubeSats could fly on and SwissCube would take one of these opportunities. In addition to the uncertainty of the launch date, other CubeSat teams were concerned with radiation environment the CubeSats might see on orbit. Some teams designed for it and others-like HiNCube and UWE-3 - opted for commercial CubeSat launches in 2013. For teams like AtmoCube and OUFTI-1, the delays caused issues with funding and student turnover that would prevent them from being able to make the Vega Maiden Flight. 
The Vega Maiden Flight went from eleven CubeSats manifested down to just six, and as the launch campaign progressed it looked like another CubeSat might not be able to recover from technical difficulties in time to make the launch. At approximately 5 months until launch, and with the manifest looking like it might only utilize five of its nine slots for CubeSats, the ESA Education Office began to informally look for any CubeSats that could meet the delivery schedule. There was interest from several CubeSat teams, but only one could deliver fully tested hardware with all of the requirement verification documentation in the short timeframe before launch. The Technical University of Budapest had been working on MaSat-1, which had completed assembly and was on the shelf waiting for a launch opportunity. The mission of MaSat-1 was to demonstrate various spacecraft avionics, including a power conditioning system, transceiver, and on-board data handling. The MaSat-1 team was able to complete all of the required testing, verification, and range documentation in less than six weeks. MaSat1, like Goliat and PW-Sat, would end up being the first satellite launched from the country in which it was developed. The final manifest comprised seven $1 \mathrm{U}$ CubeSats, with one P-POD having one flight CubeSat and two CubeSat mass models mechanically fixed to the P-POD pusher plate. The final manifest of CubeSats and the P-PODs they were integrated into is listed in Table 2. 
Table 2: Final CubeSat Manifest for The Vega Maiden Flight

\begin{tabular}{|l|l|}
\hline P-POD \#1 & University of Vigo \\
\hline XaTcobeo & Politecnico di Torino \\
\hline e-st $@$ r & University of Bucharest \\
\hline Goliat & \multicolumn{2}{|l|}{} \\
\hline P-POD \#2 & University of Montpellier \\
\hline Robusta & Technical University of Budapest \\
\hline MaSat-1 & Warsaw University of Technology \\
\hline PW-Sat & \multicolumn{2}{|l|}{} \\
\hline P-POD \#3 & University of Rome, La Sapienza \\
\hline UniCubeSat-GG & Did not separate from P-POD \\
\hline CubeSat Mass Model & Did not separate from P-POD \\
\hline CubeSat Mass Model & Did not
\end{tabular}




\section{INTERFACE CONTROL REQUIREMENTS DEVELOPMENT}

Getting a satellite to space is not easy and inherently incurs a lot of risk. The riskiest part of each space mission is the launch segment, so no matter what launch vehicle the satellite flies on there will be extensive documentation that needs to be completed by both the satellite and launch vehicle providers. Each launch vehicle will create an Interface Control Document (ICD), or in the case of the Vega launch vehicle an Interface Requirements Specification (IRS), which will contain all of the requirements and information the satellite and launch provider need to properly interface with the other's hardware. This document will contain information about mechanical, electrical, and software interfaces, as well as the dynamic and radio frequency environments each will subject the other to during ground processing and launch phases. Each requirement needs either the satellite or launch vehicle provider to submit verification documentation that will demonstrate compliance with the requirement.

For the P-PODs on the Vega Maiden Flight there were 81 interface requirements per P-POD that needed to be complied with by either Cal Poly or the launch vehicle provider. All of the requirements were documented in the P-POD to LARES Support System (LSS) IRS, which was controlled by the launch vehicle provider. Typically, during an interface requirements cycle, the requirements are at a very mature level at the time of the first IRS release and will have minor updates throughout the launch campaign. However, since this was the first flight of the Vega launch vehicle, this was not the case. The first release of the IRS was signed in March of 2009, and then went through two more revisions, in December 2009 and February 2011, which drastically changed some of the critical interface requirements and dynamic environments. This 
section will outline the critical requirements that changed and how the change in requirements was handled in order to satisfy the requirement and maintain the schedule.

\subsection{Mechanical Interface Requirements}

\subsubsection{Mechanical Interface Requirements Development}

One of the most critical interfaces between a payload and the launch vehicle is the mechanical interface. If the mechanical interfaces do not match up and the issue is not encountered until the final mate of flight hardware, then it is unlikely the payload or launch vehicle will be able to recover in time to maintain the launch schedule, and a slip in the schedule due to P-POD or CubeSat issues is not an option. In the first release of the IRS, in March 2009, the P-PODs would be mounted to their -Y face (P-POD coordinate system shown in Figure 13) with six \#10-32 bolts directly to the LSS platform, the PPOD mounting configuration is shown in Figure 14 [19].

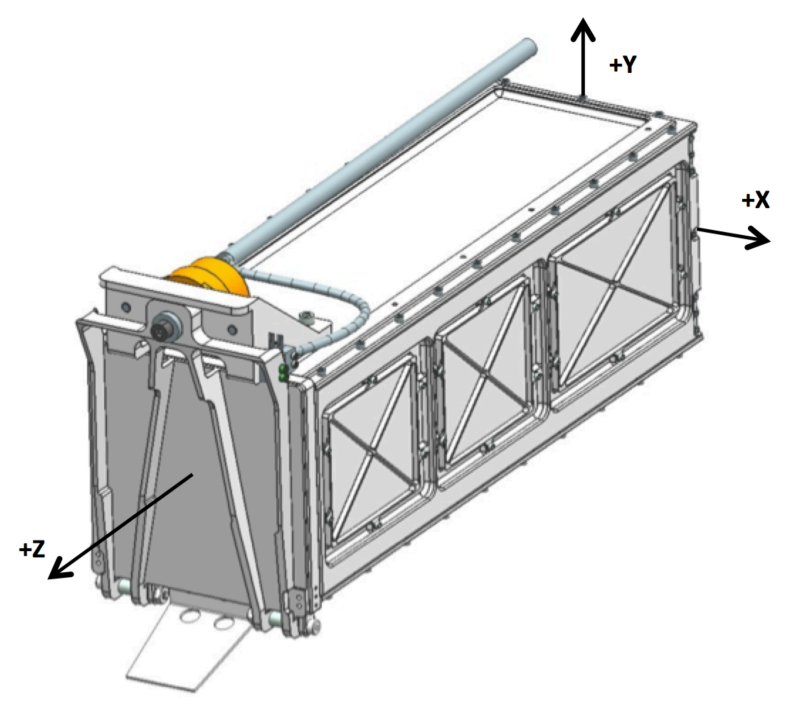

Figure 13: Mk. III P-POD Coordinate System 


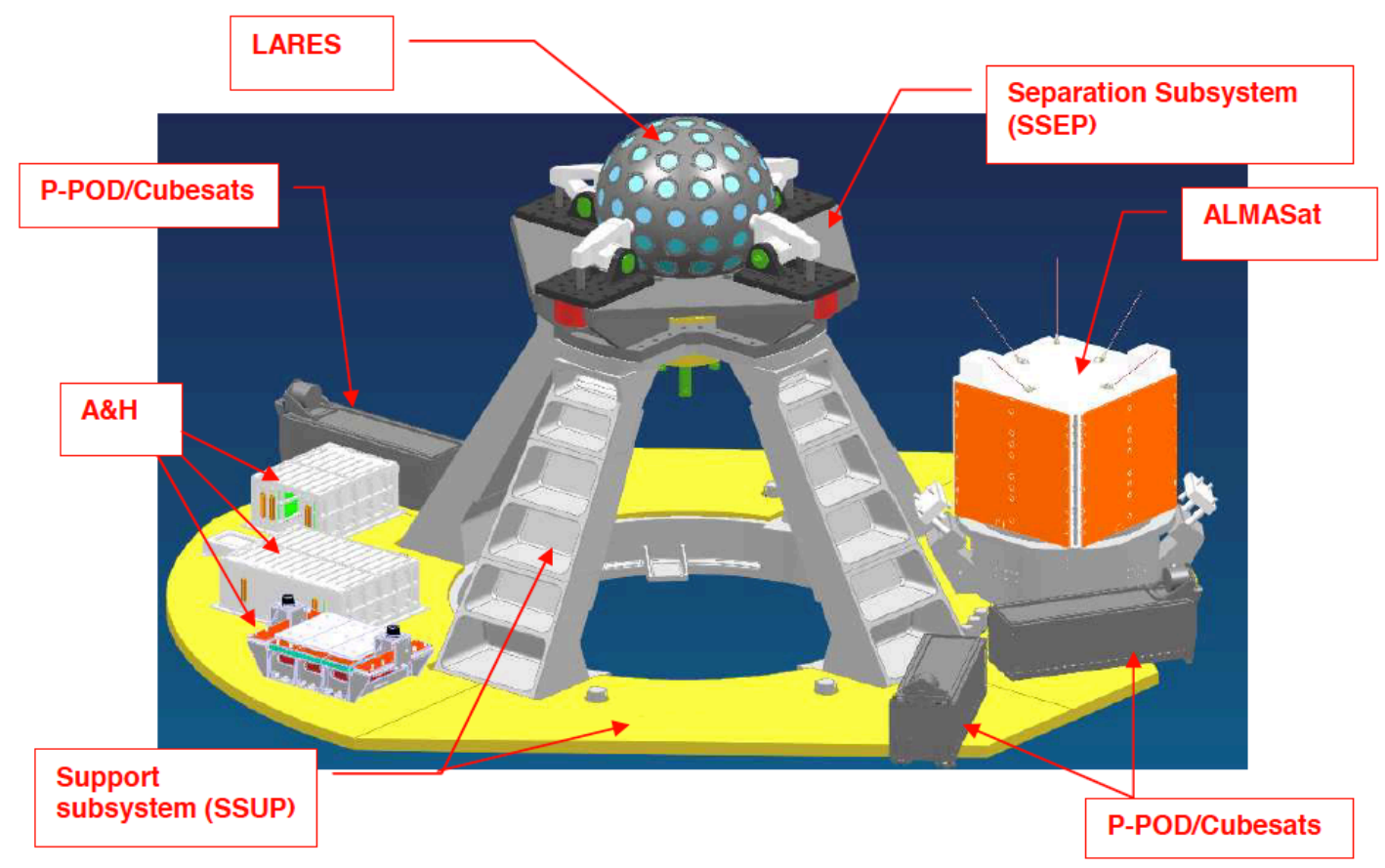

Figure 14: P-POD Mounting Configuration from the March 2009 P-POD to LSS IRS

In the next revision of the P-POD to LSS IRS, the mechanical interface for the PPODs significantly changed. In this revision, the P-PODs were to be mounted to their $+\mathrm{X}$ sides using six $1 / 4-28$ bolts mounted on an interface bracket on the LSS platform, shown in Figure 15 [13]. There were several factors that led to the changes: the first is the increased fidelity of the CAD model with other mission-unique sensors and payloads. With the addition of the sensors and avionics boxes, there was now less surface area for the P-PODs to be mounted on the LSS platform. The next was the request from the ESA Education Office to have the P-PODs mounted in such a way that they could be mounted as late in the integration flow as possible. The Education Office started thinking about contingency plans due to CubeSat development delays very early in the launch campaign. The P-PODs being mounted to an interface bracket that was near perpendicular to the LSS platform meant that the brackets could be installed early in the integration flow and 
the P-PODs could be added at any time with easy access to the P-POD mounting bolts. The change in the size of the mounting bolts was a request from the Education Office, which, in-turn, drove the change of the mounting side of the P-POD. Since the P-POD wall is thicker on its X sides, it can accommodate a larger mounting bolt and still satisfy minimum thread engagement requirements.

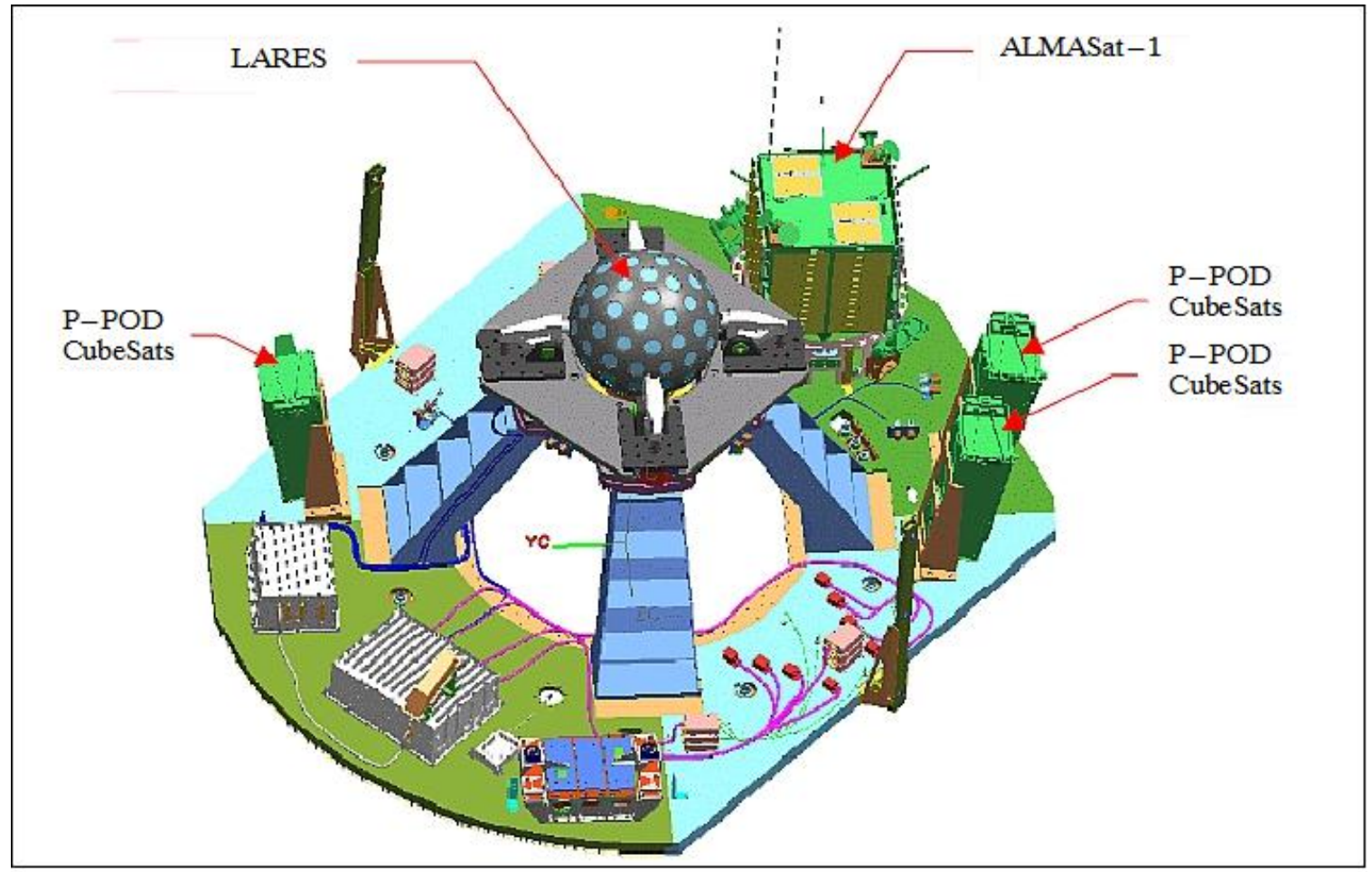

Figure 15: P-POD Mounting Configuration from the December 2009 P-POD to LSS IRS

\subsubsection{Resolution for P-POD Mechanical Interface Requirements Change}

At first glance, the resolution for change with the P-POD mechanical interface requirements appears straightforward: comply with the requirements in the December 2009 revision of the IRS. However, there are other, non-technical factors the ESA Education Office needed to consider. 
This mission was the first flight of the Vega launch vehicle, which meant that the requirements could change again closer to launch. Additionally, since this was the first flight of the Vega launch vehicle, the development could have been delayed enough that it would make more sense for the Education Office to find another launch opportunity, which could have different mounting requirements for the P-POD. Since certain aspects of the P-POD's mounting configuration are driven by its design, the two mounting configurations that were already proposed were the only two options available. Accordingly, if the mounting configuration had to change, either from Vega or a different launch vehicle's requirement, the mounting configuration would change back to the configuration specified in the March 2009 revision of the IRS. Also, at this point in the launch campaign there were several CubeSats that had already announced they would not be accepting the Education Office's offer of a free flight on the Vega Maiden Flight and would fly on another commercial launch opportunity. This meant there was a possibility that there would not be enough CubeSats to fill all of the P-PODs. If that were the case, the Education Office would want to fly the unused P-POD(s) on another launch opportunity, which would not necessarily use the same mounting pattern.

After Cal Poly discussed the different options with the Education Office, both parties decided the P-PODs would be built with both mounting configurations. The rationale was that if the P-PODs had both mounting configurations, the P-POD assembly could move forward, independently from the IRS development, and with little risk of not being compliant the P-POD to LSS IRS. The additional mounting configuration would give the Education Office more flexibility if the P-PODs needed to fly on a different launch opportunity. The addition of the second mounting hole pattern would give the P- 
POD more ventable area, which would make it easier to comply with ascent venting requirements for the mission, and if the other mission partners did not like the extra holes in the P-POD, they could easily be plugged with short bolts. This was the first, and only, time that a P-POD has flown with multiple mounting hole patterns on the same unit.

\subsection{Electrical Interface Requirements}

\subsubsection{Electrical Interface Requirements Development}

The electrical interfaces between the P-POD and the launch vehicle include the electric signals that are sent to the P-POD to actuate the door release mechanism, receive telemetry of the position of the P-POD door, and the connectors that each side uses to mate harnesses together. If there is an issue with the electrical interfaces between the PPOD and the launch vehicle, then the P-POD's door will not open and deploy the CubeSats. According to the first revision of the IRS, each P-POD would have two U.S. military specification connectors. One connector would have two circuits for the primary and redundant fire and return signals for the P-POD door release mechanism and the other connector would have two circuits for the primary and redundant door position telemetry signals, shown in Figure 16. 


\begin{tabular}{|c|c|c|}
\hline \multirow{4}{*}{$\begin{array}{c}\text { P-POD } \\
\text { Connector }\end{array}$} & Primary Switch Signal & \multirow{2}{*}{$\begin{array}{l}\text { Switch } \\
\text { (Primary) }\end{array}$} \\
\hline & \multirow{2}{*}{$\begin{array}{l}\text { Primary Switch Return } \\
\text { Redundant Switch Signal }\end{array}$} & \\
\hline & & \multirow{2}{*}{$\begin{array}{l}\text { Switch } \\
\text { (Redundant) }\end{array}$} \\
\hline & Redundant Switch Return & \\
\hline
\end{tabular}

\begin{tabular}{|c|c|c|}
\hline \multirow{4}{*}{$\begin{array}{c}\text { P-POD } \\
\text { Connector }\end{array}$} & Primary Actuation Signal & \multirow{4}{*}{$\begin{array}{c}\text { P-POD Door } \\
\text { Release } \\
\text { Mechanism }\end{array}$} \\
\hline & Primary Actuation Return & \\
\hline & Redundant Actuation Signal & \\
\hline & Redundant Actuation Return & \\
\hline
\end{tabular}

Figure 16: P-POD Electrical Interface Configuration from The March 2009 IRS

In the December 2009 revision of the IRS, the electrical interfaces would change due to a change in implementation of redundancy for the P-POD. The P-POD would still require two connectors, but each connector would have one circuit for the P-POD door release mechanism and another circuit for the P-POD door position telemetry signals, shown in FIG. Also, the connectors would change from U.S. military specification to connectors with European specifications. 


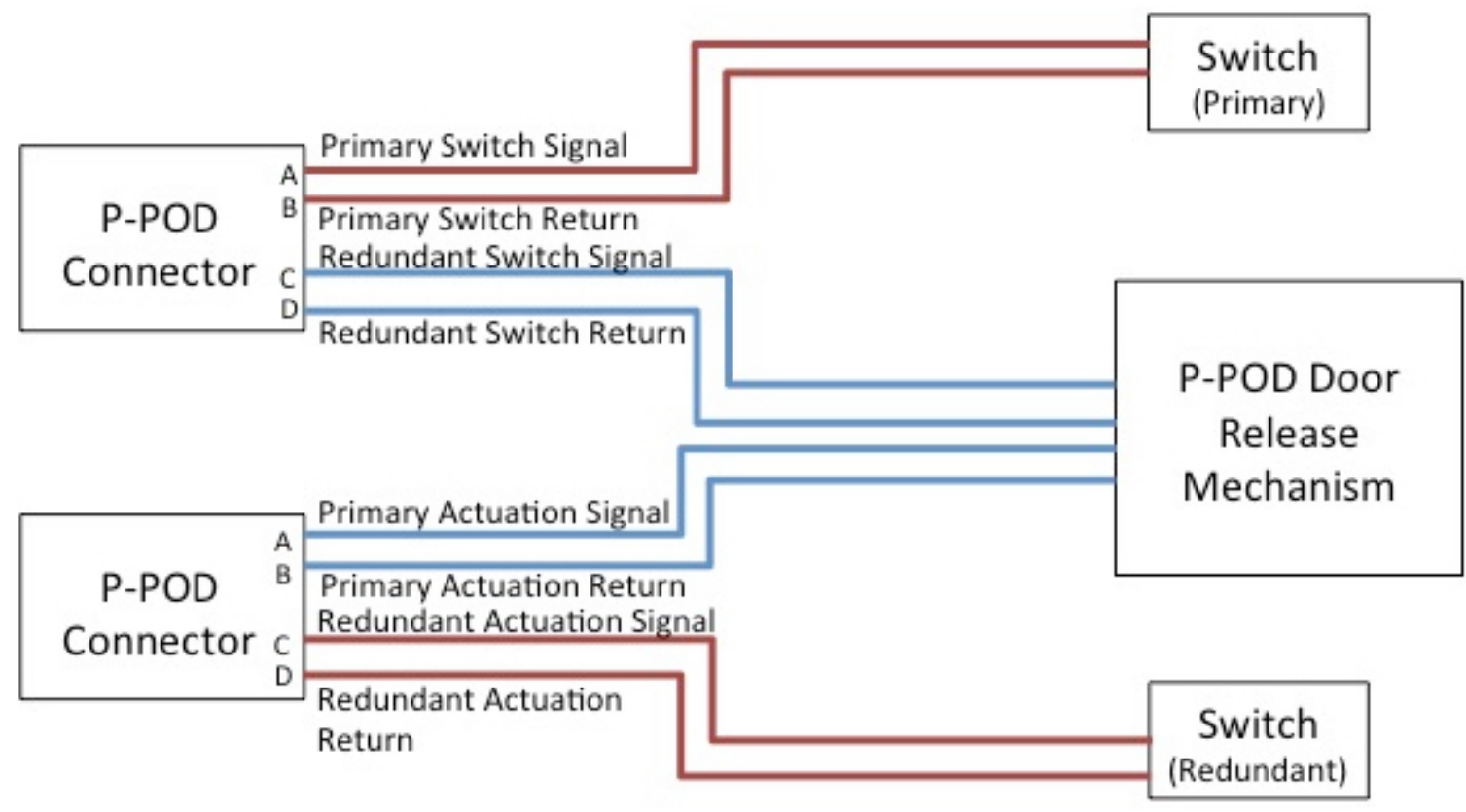

Figure 17: P-POD Electrical Interface Configuration from The December 2009 IRS

\subsubsection{Resolution for P-POD Electrical Interface Requirements Change}

Since the P-POD electrical harnesses had not been built before the December 2009 revision of the IRS, the change of the function of the P-POD connectors was implemented without any setbacks. However, the change in specification and part number of the P-POD connectors caused more difficulties. First, the part numbers related to European specifications, so Cal Poly had to determine the U.S. crossover part number for the connectors. To get the crossover part numbers took a couple of weeks of calling connector vendors until someone could translate them to a part number that U.S. vendors could understand. Then it took another couple of weeks to try to find a vendor that could manufacture the connector, and none could be found. After discussing the issue with the ESA Education Office, it was determined they would procure the connectors for the PPODs and a certified ESA technician would install the connectors after the P-PODs were 
delivered to ESTEC. The Education Office liked this plan because a certified ESA technician would close out the P-POD harnesses. However, this would delay most of the P-POD electrical verification documentation, because the P-POD harnesses would not be completed until delivery to ESTEC.

\subsection{Random Vibration Requirement}

\subsubsection{Random Vibration Requirement Development}

Any payload on a launch vehicle must be compliant with the dynamic loads subjected to it during launch, and for small payloads the most severe dynamic environment is typically the random vibration environment. The random vibration levels for most payloads are derived from flight data from previous flights, but since this was the first flight of the Vega launch vehicle, there was no flight data. In the first revision of the IRS, there was a random vibration environment specification with levels and durations for acceptance and qualification testing for the P-POD interface. The acceptance specification for the P-PODs was an $8.81 \mathrm{Grms}$ profile to be tested in each axis for 2 minutes per axis. The qualification specification was a $13.98 \mathrm{Grms}$ profile to be tested in each axis for 2.5 minutes per axis. The difference between the acceptance and qualification levels and durations was much smaller than usual. The differences did not trace back to any European Cooperation for Space Standardization (ECSS) or U.S. specifications or standards. The qualification levels were lower than normal due to the conservatism used to derive the acceptance levels and durations.

For the next revision of the IRS in December 2009 the random vibration levels remained the same. However, in the February 2011 revision of the IRS the random 
vibration levels changed. The acceptance specification for the P-PODs was a $4.10 \mathrm{Grms}$ profile to be tested in each axis for 2 minutes per axis. The qualification specification was a $6.49 \mathrm{Grms}$ profile to be tested in each axis for 2.5 minutes per axis. The levels were updated after modal characterization testing was performed of the LSS with LARES, an engineering unit P-POD, and mass models representative of the other payloads and subsystems on the flight, shown in Figure 18.

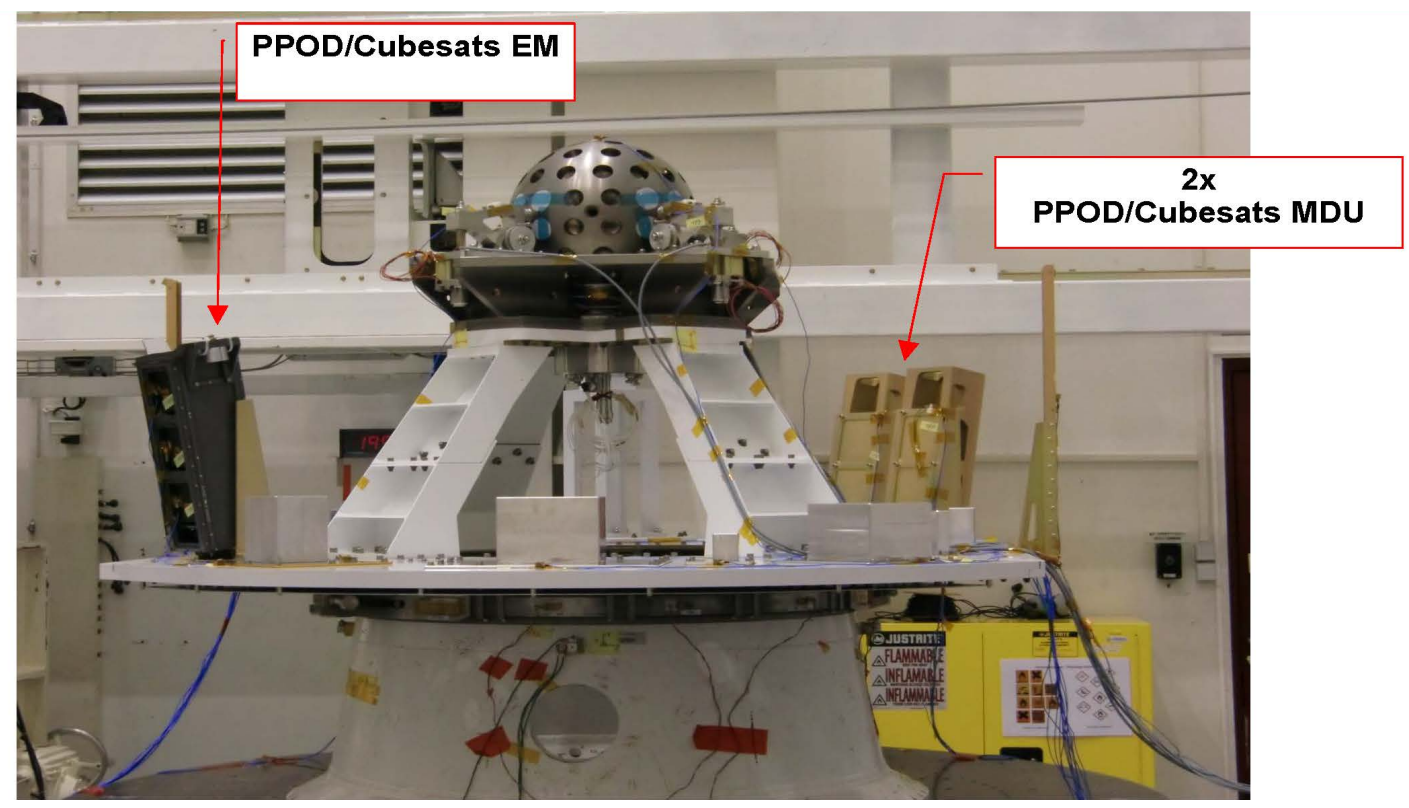

Figure 18: LARES with an Engineering Unit P-POD on the LSS for Characterization Testing

\subsubsection{Resolution for The Change to The Random Vibration Requirement}

The change of the random vibration requirement came late in the launch campaign. The levels were received in February 2011, and, at that time, the P-PODs were to be delivered to ESTEC in July 2011. Fortunately, the levels were lower than previous revisions of the IRS and the P-PODs had not been tested yet, so this change in 
requirement—even though it came very late in the flow—did not cause a situation where the P-PODs were not compliant or over-tested. If the P-PODs had been tested to the previous levels, they could have been considered over-tested and their flight worthiness could have been brought into question.

\subsection{Sine Vibration Requirement}

\subsubsection{Sine Vibration Requirement Development}

Sine vibration testing is intended to simulate sustained sine and transient events that occur during launch [20]. For small payloads and components the random vibration environment typically encompasses the sine vibration environment. In the first two releases of the IRS there was no sine vibration environment specified, nor was there even a placeholder for such information. So, when the February 2011 revision of the IRS was released with a sine vibration environment, it came as a surprise especially since the hardware was to be delivered to ESTEC in just a few months. A typical sine vibration environment is specified from 5 to $100 \mathrm{~Hz}$ to replicate the low frequency launch environment; however, the specification in the IRS ranged from 10 to $200 \mathrm{~Hz}$. Usually the specification will not exceed the range that the Coupled Loads Analysis (CLA) is performed, which would be $100 \mathrm{~Hz}$. Also, the sine vibration environment for acceptance testing had levels that exceed $20 \mathrm{G}$ 's in the 30 to $100 \mathrm{~Hz}$ range.

\subsubsection{Resolution for The Change to The Sine Vibration Requirement}

The addition of the sine vibration environment would not have caused much concern if the environment had been known earlier and if the levels were not as severe. The sine vibration environment came after the characterization testing of the LSS, and 
was a known event, but was assumed to verify the levels of the previous IRS revisions. As with the random vibration environment, the qualification levels for the sine vibration environment were only slightly higher than the acceptance levels. Again, this was due to the conservatism used when deriving the acceptance sine vibration levels.

The first thing that Cal Poly had to do was find out whether the P-POD could survive the sine vibration environment. Analysis was performed, using conservative factors of safety, on the P-POD with the given environments. The analysis showed that the P-POD should survive with the sine vibration environment with a positive margin of safety. However, the levels were high enough that the testing could not be performed on any of the vibration tables at Cal Poly. Again, with the P-PODs due to be delivered in just a few months, this issue could have been devastating. Luckily, Cal Poly had been working two other missions with high random vibration levels, which required a third party vendor to perform that testing, so Cal Poly had already been in contact with several vendors that were known to be able to perform the sine vibration testing at a reasonable cost and with little impact to the schedule. If Cal Poly had more experience with sine vibration environments on other launch vehicles, Cal Poly would have pushed back on this environment or at least inquired to how this environment was derived. The frequency range for this environment went up to $200 \mathrm{~Hz}$, which most sine vibration environments only go to up to 50 or $100 \mathrm{~Hz}$. Also, the acceleration levels over $20 \mathrm{G}$ 's in some frequency ranges did not seem realistic. 


\subsection{Shock Requirement}

\subsubsection{Shock Requirement Development}

The shock environment for a payload on a launch vehicle is derived from events that generate shock, such as stage, faring, and primary payload separation events. The shock environment for small payloads, like the P-POD, is usually relatively benign when compared to the random vibration environment. In the first two revisions of the IRS, the shock requirement was derived from an ECSS document, ECSS-E-10-03A, for general guidelines for environmental testing [21]. The requirement from the ECCS document states, "the shock spectrum in each direction of the three orthogonal axes shall be equivalent to a half sinusoidal pulse of $0.5 \mathrm{~ms}$ duration and $200 \mathrm{G}$ (0-peak) amplitude," which is shown in Figure 19. This shock environment is relatively benign and could be satisfied with a simple analysis, and no testing would be required.

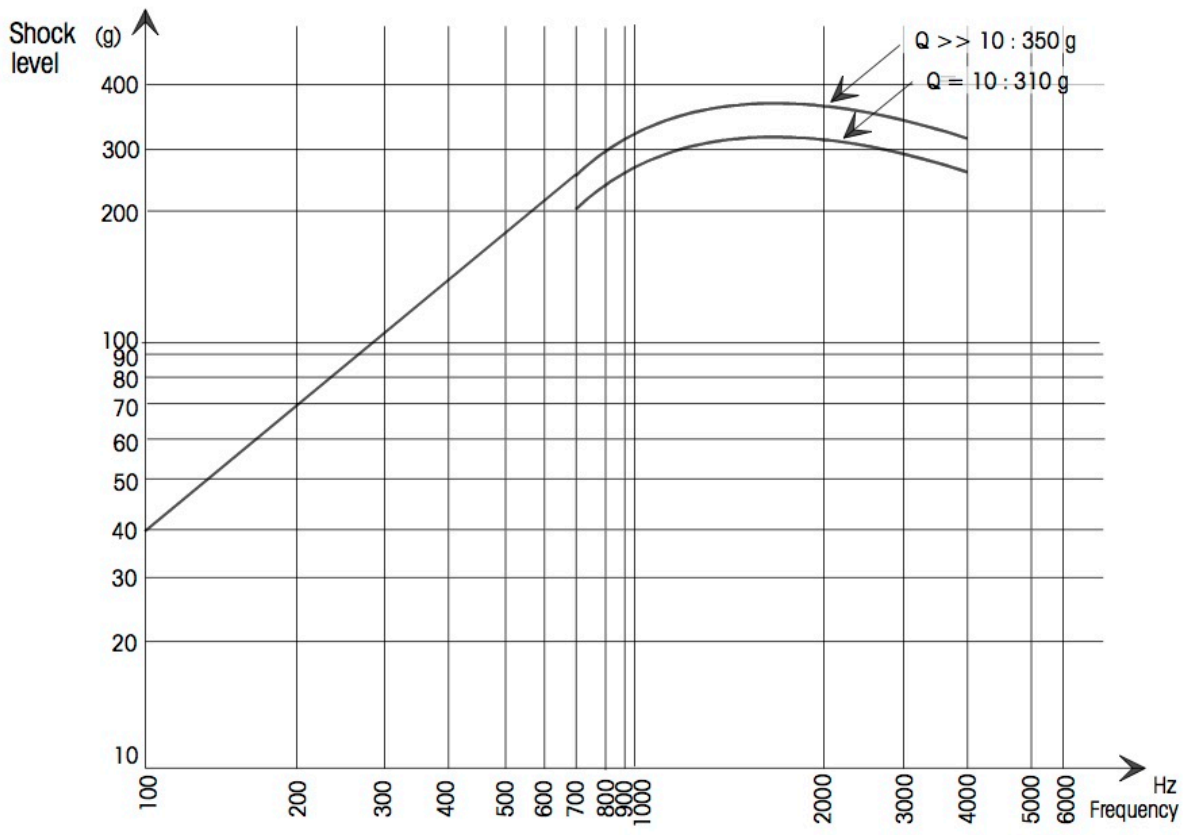

Figure 19: Shock Spectrum for Equipment Qualification From ECSS-E-10-03A 
In the February 2011 revision of the IRS, the shock qualification spectrum changed drastically. The shock spectrum was defined in a Shock Response Spectrum (SRS) plot, with a frequency range from 100 to $10,000 \mathrm{~Hz}$ with a maximum acceleration of 5,000 G's. This new shock specification was no longer considered to be benign, and performing analysis to satisfy this requirement would be extremely difficult.

\subsubsection{Resolution for The Change to The Shock Requirement}

The timing for the change of the sine vibration and shock requirements provided the most concern that the P-PODs might not be able to make the delivery date to ESTEC for CubeSat integration. In fact, this requirement was not officially completed until after the P-PODs were mounted to the launch vehicle. Cal Poly had previously performed shock testing on P-PODs and CubeSats, but those tests were extremely costly and were not covered as part of the statement of work or the budget. Since analysis could not be performed, Cal Poly was left with two options; either perform the shock test on a P-POD engineering unit to Vega specifications or supply data for qualification by similarity. Luckily, Cal Poly had been working two other missions on different launch vehicles with a shock environment that needed to be tested to qualification.

While neither of the profiles from the other launch vehicles specified accelerations as high as the Vega launch vehicle, the inherent over-testing that occurs during shock testing was able to save the day in this instance. Since shock testing is applied in a sort of trial-and-error method, and one of the typical requirements is to have at least $50 \%$ of the data points be over the test specification, MIL-STD-1540, it is difficult not to over test the hardware especially in the higher frequency ranges. Initially, 
Cal Poly presented the as-tested shock results from the other two test campaigns overlaid the Vega shock specification. While each test did not quite show compliance across the entire spectrum, if you combined the two tests it was compliant. In the end, ASI and ESA approved the superposition of the data from the two tests and a review of the materials of the P-POD to show there were no items that were easily subjected to failure due to the shock environment.

\subsection{Thermal Environment}

\subsubsection{Thermal Environment Development}

The IRS for a given launch vehicle typically will only specify the heat fluxes that the will be encountered during flight. It is then up to the launch vehicle or spacecraft provider to use those heat fluxes as input into a thermal analysis. For the P-PODs on the Vega flight, it was up to Cal Poly and ESA to complete the thermal analysis. The first two revisions of the IRS supplied preliminary information for the heat flux inputs to the P-POD interface, but these inputs were determined to be unrealistic and the thermal analysis would be performed after the next iteration of inputs were received. The final revision of the IRS in February of 2011 provided usable inputs for the thermal analysis. The limiting factors for the allowable range of temperatures of the integrated P-PODs are the CubeSats, typically due to the CubeSat's batteries. The CubeSat batteries are the primary limiting factor for the range of temperatures that the CubeSats can survive, which is approximately between $0^{\circ} \mathrm{C}$ and $50^{\circ} \mathrm{C}$, while in operation, the range is larger while the spacecraft is powered off. In order to simplify the analysis, the ESA Education Office decided to add the requirement that the P-POD walls should not be warmer that 
$60^{\circ} \mathrm{C}$ in order for the CubeSats to remain below their limit. The requirement was levied on the P-POD because the P-POD thermal model, shown in Figure 20, was a low fidelity model, which was only made up of 6 nodes and did not explicitly account for the CubeSats inside [22].

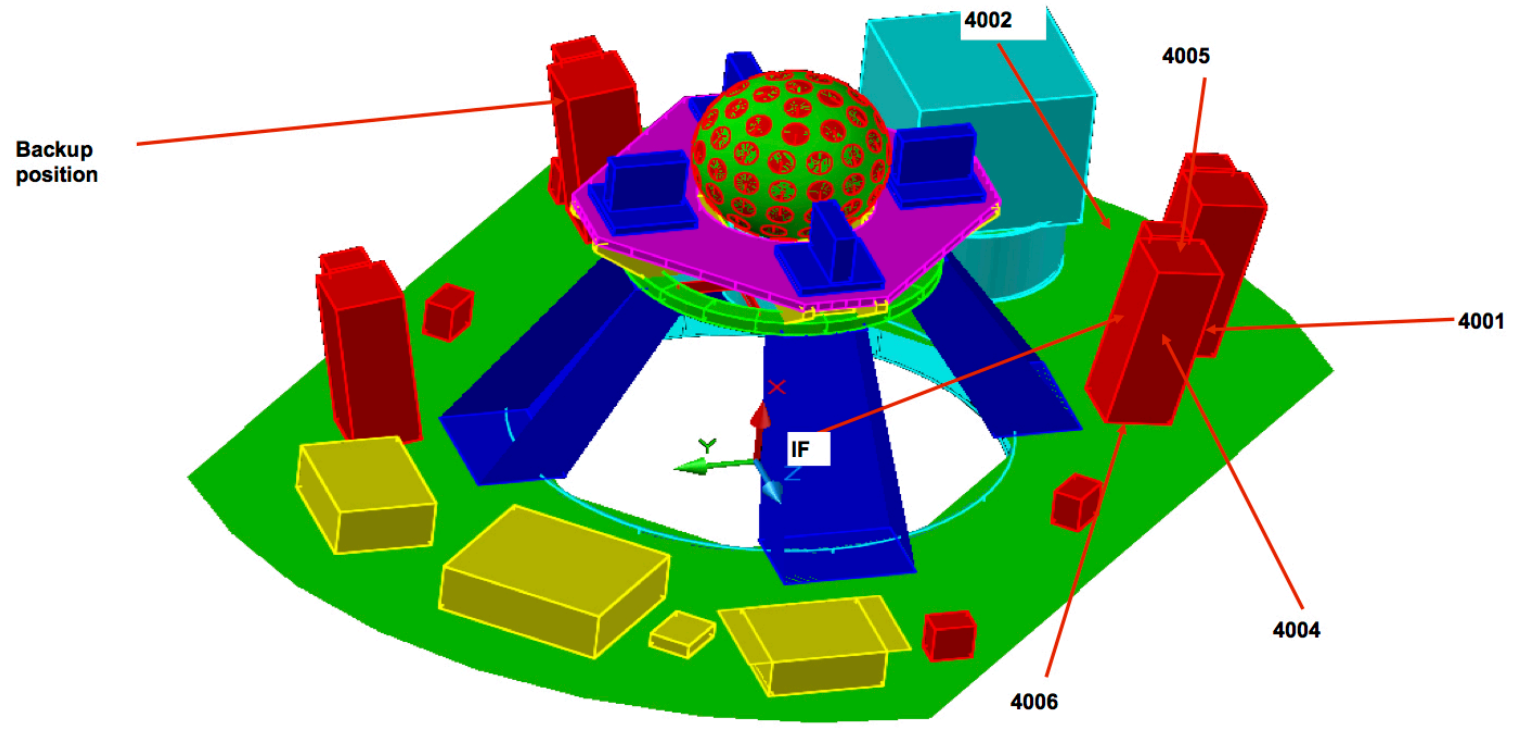

Figure 20: LSS Thermal Model with P-PODs

The analysis was performed without any addition of thermal hardware, such as washers, between the P-POD and its mounting bracket, or different surface coatings on the P-POD. The analysis was performed for the duration of the flight, taking into account the conduction between the P-POD and its mounting bracket and the sources of radiation. The maximum P-POD temperature was determined to be $85^{\circ} \mathrm{C}$ without adding uncertainty, shown in Figure 21 [22]. A standard uncertainty factor for ESA for thermal analysis without any previous flight data is $+/-20^{\circ} \mathrm{C}$. So, after adding the uncertainty to the upper value, the P-POD's highest temperature would be $105^{\circ} \mathrm{C}$, which would be too hot for the CubeSat batteries. 


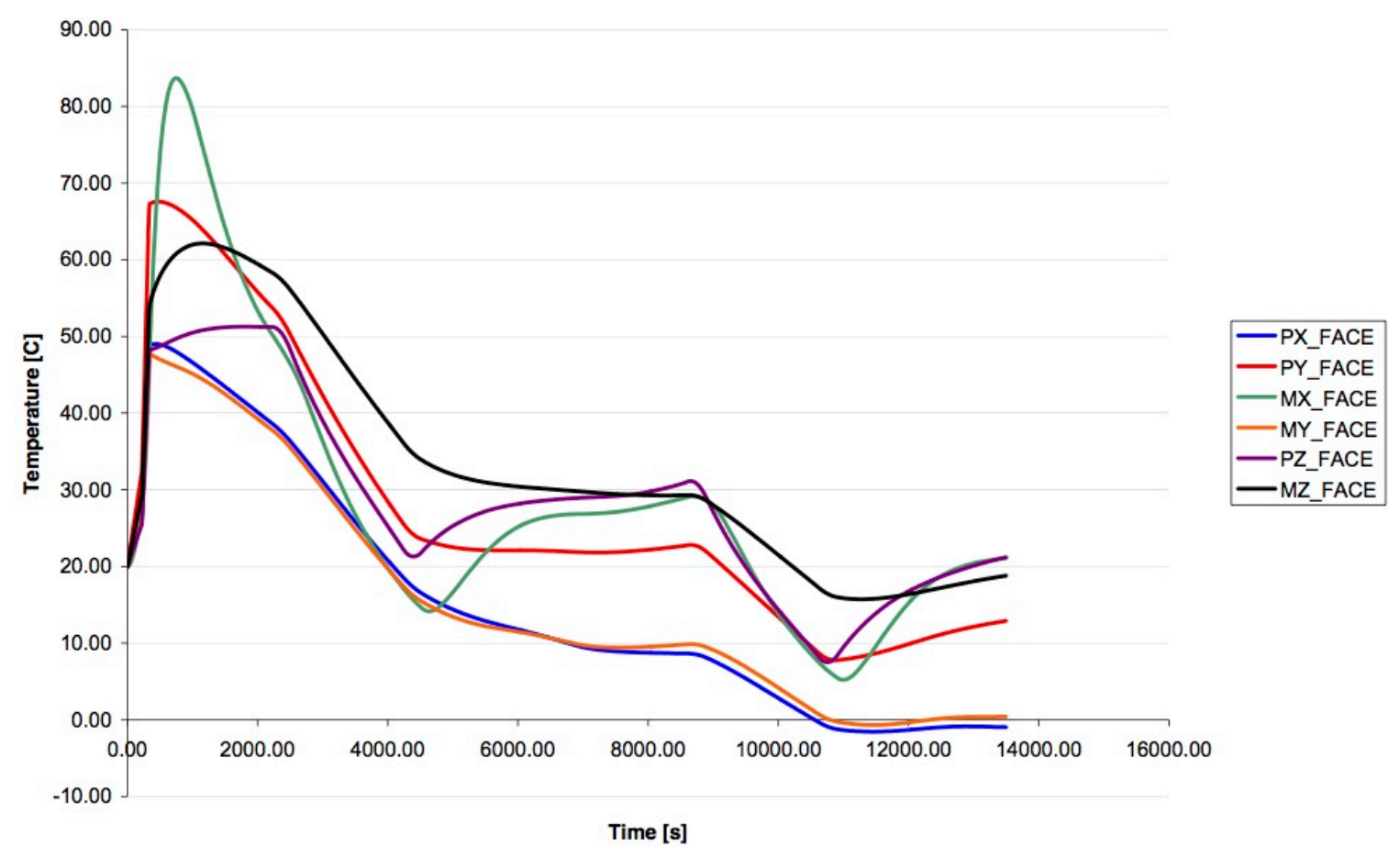

Figure 21: P-POD Wall Temperatures Without Uncertainty Factors Applied

\subsubsection{Resolution for The Change to The Thermal Environment}

Once again, there was another requirement change to the IRS in the February 2011 revision, which would add to the concern that the P-POD would not be able to make the schedule. In order to meet the thermal requirements of the P-POD, there would have to be some sort of design change or addition to the P-POD.

The first considered option that would get the P-POD temperatures within limits the CubeSats could safely survive was to add a washer with low thermal conductivity to reduce the amount of heat transferred to the P-POD from its mounting bracket. The results would show an improvement with the predicted peak temperature of the P-POD now being $68^{\circ} \mathrm{C}$, without uncertainty, shown in Figure 22 [22]. However, for slightly more than 4000 seconds, the predicted temperatures of all the P-POD faces exceed $50^{\circ} \mathrm{C}$, 
after the $20^{\circ} \mathrm{C}$ uncertainty factor is applied. Though the washers improved the results, they were not enough to ensure a safe environment for the CubeSats. Further investigation was needed to adjust the thermo-optical properties of the P-POD.

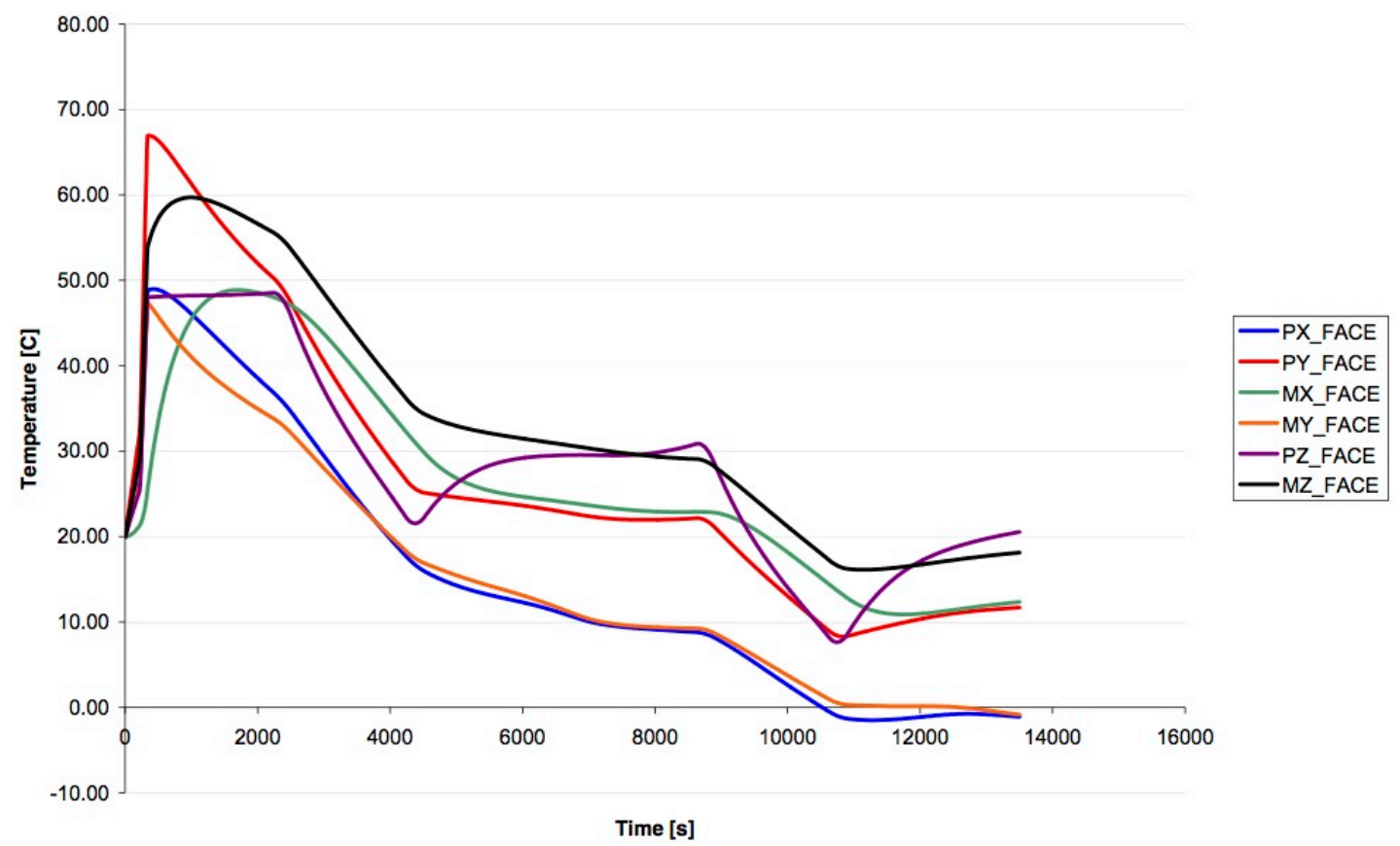

Figure 22: P-POD Wall Temperatures with Thermal Washers and Without Uncertainty Factors Applied

For the next iteration of the thermal analysis, the ESA Education Office decided to decouple the P-POD's $-\mathrm{X},-\mathrm{Y}$, and $+\mathrm{Y}$ faces from the bracket; therefore a very low emissivity coating was used. The $-\mathrm{Z}$ face of the P-POD, which points at the LSS platform, was also covered with a low emissivity coating to avoid overheating. Finally, in order to reject any residual heat from the P-PODs, a high emissivity coating was selected for the P-POD's $+Z$ and $+X$ faces. This iteration of the thermal analysis also used the thermal washers from the previous iteration. The results showed that all of the temperatures are below $50^{\circ} \mathrm{C}$ specification, with uncertainty, except for the $+\mathrm{Y}$ and $-\mathrm{Z}$ 
faces of the P-POD, shown in Figure 23 [22]. However these faces only exceed $50^{\circ} \mathrm{C}$ for a short period of time, and it was determined that the CubeSats would not get above $50^{\circ} \mathrm{C}$ for the duration of the flight. There modifications were considered the optimum thermal configuration for both the hot and cold cases for the P-POD and CubeSats.

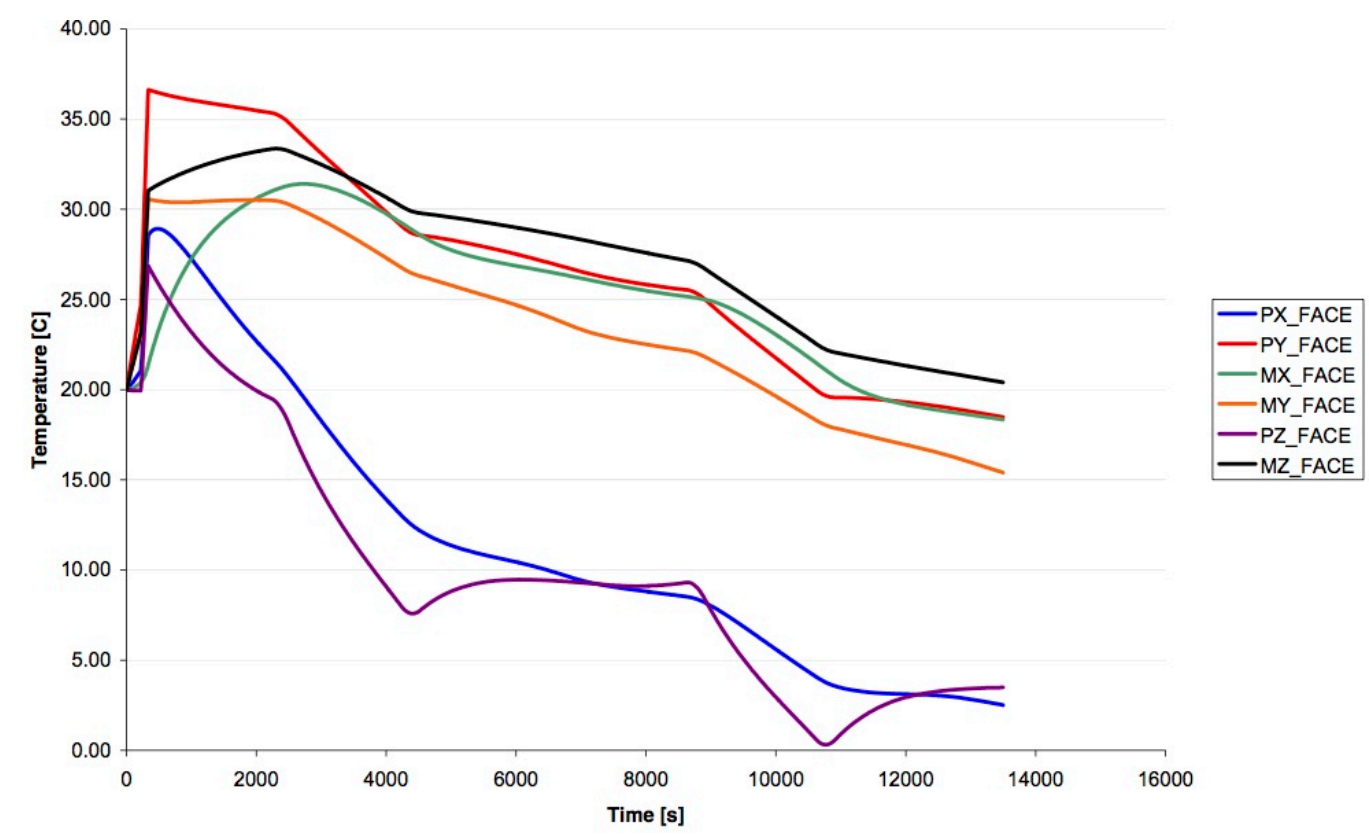

Figure 23: P-POD Wall Temperatures with Surface Coatings and Thermal Washers and Without Uncertainty Factors Applied

At this point in the launch campaign, the P-PODs were already built, but not tested. In order to meet the optical properties of the surface coating specified in the thermal analysis, Cal Poly needed to acquire thermo-optical tape. The Education Office specified a Vacuum Deposited Aluminum (VDA) kapton tape and silver Teflon tape to meet the requirements of the surface coatings. The tape also needed to be perforated in order to mitigate any risk of the tape delaminating during ascent due to air bubbles under the tape. The only known manufacturers of tapes with these specifications were located in the U.S., so Cal Poly had to order the thermal tape. However, the manufacturers for the 
thermal tape only sell minimum quantities, which were more than twice as much as needed for the three P-PODs and were relatively expensive. The thermal tape also had a four-to-six week lead-time, following an official purchase order with the manufacturer. Fortunately, Cal Poly was able to place the order to get the thermal tape by the end of June 2011, which was only three months before the P-PODs were delivered to ESTEC. The procurement of the thermal tape and the requirement from the ESA Education Office to have the tapes applied, at least for thermal vacuum bakeout, would negatively affect the schedule. This meant that Cal Poly could not start the environmental testing of the PPODs until the thermal tape could be applied to them. The addition of the thermal tape on the P-PODs prior to testing would make the P-PODs more difficult to handle. Since the there are areas that are taped that are not attached to the P-POD structure, such as the harness, the thermal tape in those areas could be easily ripped and once a tear starts in a piece of the tape, it would quickly propagate across that entire piece of tape. 


\section{SYSTEM LEVEL ENVIRONMENTAL TESTING}

The ESA Education Office developed the test flow for the CubeSats and P-PODs on the Vega Maiden Flight with input from Cal Poly. The test flow for P-PODs and CubeSats tends to be somewhat conservative in order to prove to the primary payload and launch vehicle that they will not cause any harm. Usually, the P-PODs and CubeSats go through testing separately prior to integration and then go through acceptance or workmanship testing after the CubeSats have been integrated into the P-POD. For this mission, it was decided that the CubeSats and P-PODs would go through random vibration, sine vibration, and thermal vacuum bakeout testing prior to being integrated with each other. Then the integrated system would go through an acceptance vibration test, the general test flow is shown in Figure 24. The CubeSats and P-POD showed compliance with the acoustic environment through analysis. The shock environment would be satisfied by analysis for the CubeSats and qualification by similarity for the PPODs. 
CubeSat Qualification

Random Vibration Test

(150\% of Acceptance

P-POD Random

Levels)

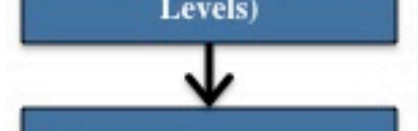

CubeSat Qualification

Sine Vibration Test

(125\% of Acceptance

Levels)

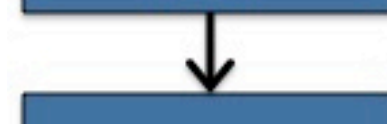

CubeSat Thermal

Vacuum Bakeout Test

Vibration Test
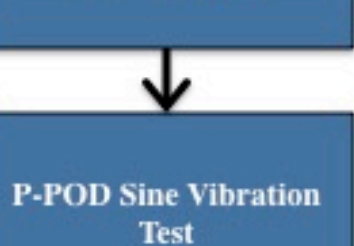

Test

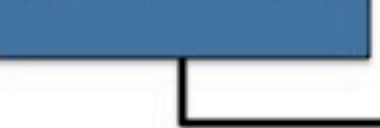

P-POD Thermal

Vacuum Bakeout Test

CubeSat to P-POD

Integration

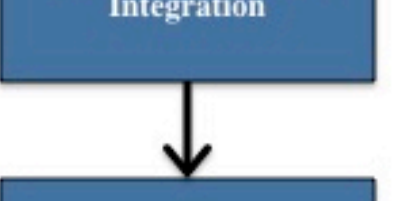

Integrated P-POD

Acceptance Random

Vibration Test

Figure 24: P-POD and CubeSat Test Flow for The Vega Maiden Flight

\subsection{CubeSat Test Flow}

Prior to CubeSat delivery to ESTEC for integration into the P-POD, each CubeSat had to go through vibration and thermal vacuum bakeout testing. The CubeSats were required to go through qualification random vibration and sine vibration testing as specified by the P-POD to LSS IRS. The random vibration qualification levels were only $150 \%$ of, and 0.5 minutes longer than, the acceptance levels. The sine vibration qualification levels were $125 \%$ higher than the acceptance levels. Both of these levels 
would be considered proto-flight levels, not qualification, by U.S. standards such as MILSTD-1540, but there was little concern or risk that these levels would be hazardous to the flight hardware. These tests were to be performed in a TestPOD, shown in Figure 25, which is a structure that is similar to the P-POD, but intended to be the interface between the CubeSat and the vibration table to simulate the environment inside the P-POD. The CubeSats would also have to go through thermal vacuum bakeout specified by the CubeSat to P-POD ICD [23]. These tests were to be performed by the CubeSat teams, either at their own facilities or third party facilities, or in some cases at ESTEC. All test reports had to be submitted and approved by the ESA Education Office prior to CubeSat integration to the P-POD.

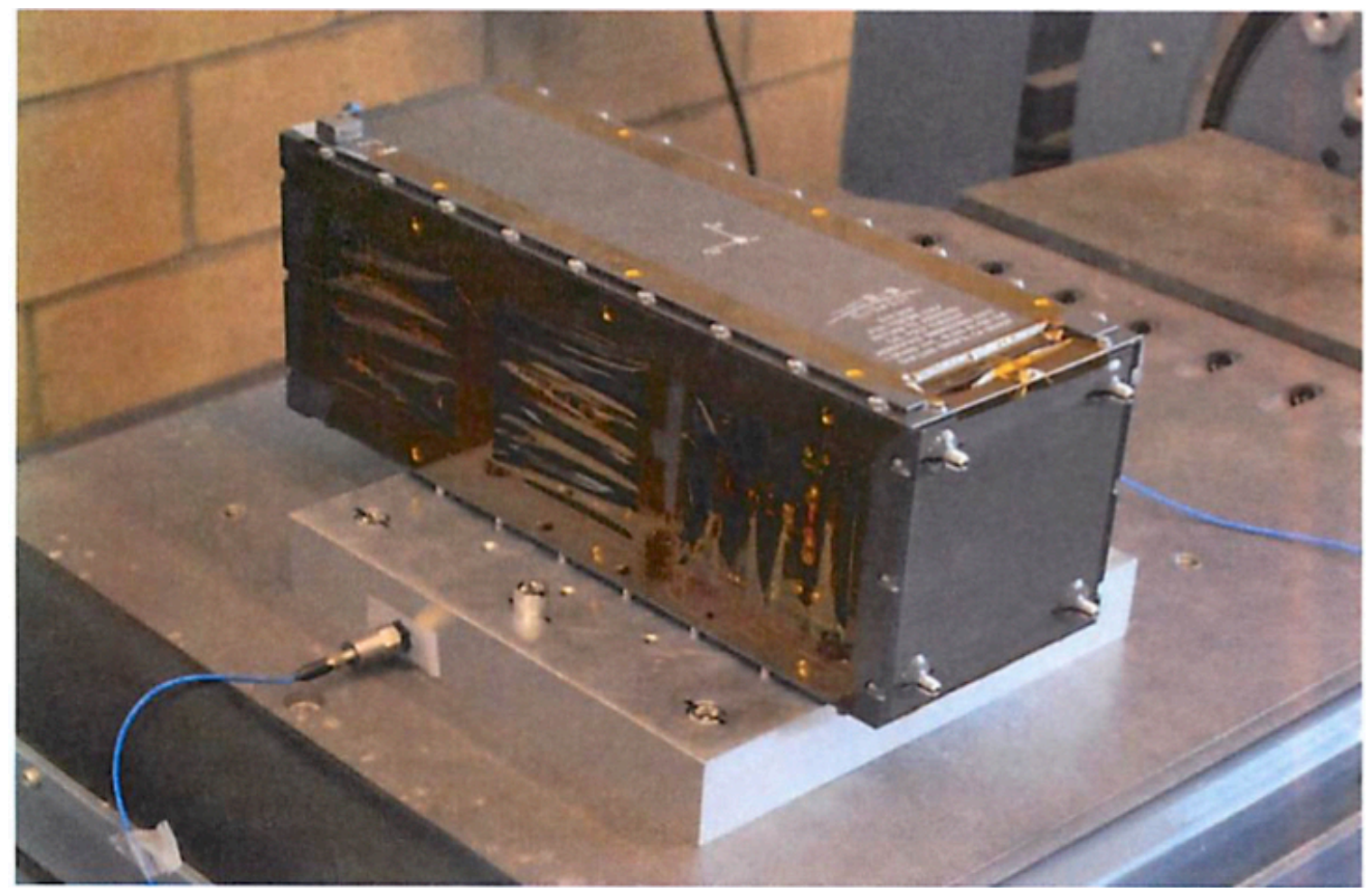

Figure 25: Cal Poly 3U TestPOD on a Vibration Table 


\subsection{P-POD Test Flow}

The P-POD test flow differed slightly from the CubeSat test flow. Since there were three identical P-PODs flying on this mission, all three units did not need to go through qualification testing. One P-POD underwent qualification random and sine vibration testing, while the other two P-PODs underwent acceptance random and sine vibration testing. The rationale for this test flow is that once the design was qualified, there was no need to stress the other flight hardware unnecessarily. However, all three PPODs would go through thermal vacuum bakeout testing. These tests were to be performed at Cal Poly facilities, except for the sine vibration testing, which was performed at a third party's facilities. All test reports were submitted and approved by the ESA Education Office prior to CubeSat integration to the P-POD.

\subsection{Integrated P-POD Test Flow}

After the CubeSat and P-POD documentation was accepted and approved by the ESA Education Office, the hardware would be delivered to ESTEC for CubeSat to PPOD integration. After the CubeSats were integrated into the P-PODs, the integrated PPODs underwent a final acceptance random vibration test. This test was to verify proper workmanship of the P-PODs after CubeSat integration. This test was performed at a third party vendor's facility in Toulouse, France. After this test all the environmental test documentation was submitted to the Vega Integrated Payload Team (IPT) for final approval. 


\section{CUBESAT TO P-POD INTEGRATION}

\subsection{Methodology}

The CubeSat to P-POD integration milestone required the delivery of the flight CubeSats and P-PODs to ESTEC after they had successfully completed the required environmental testing. After the P-PODs were delivered to ESTEC, the ESA Education Office inspected them, and the connectors were attached to the P-POD harnesses by an ESA technician. After delivery of the CubeSats, they were inspected by Cal Poly to ensure proper fit in the P-POD, and by the ESA Education Office to ensure proper function and that the hardware matched documentation previously provided.

After CubeSat to P-POD integration, the final random vibration testing of the integrated system was performed. The CubeSats cannot be removed from the P-POD after testing unless there is a potential danger to the satellites or the launch vehicle. Posttest inspections and diagnostics of the CubeSats were performed through the access ports on the P-POD.

Post-test inspections and diagnostics of the CubeSats after environmental testing may uncover malfunctions or failures. Physical removal of the CubeSats from the P-POD is not allowed, as it will compromise the final system level test. However, if the failure could pose harm to the launch vehicle or other payloads, then the CubeSat would need to be de-integrated from the P-POD in order to address the failure. The extent of the repairs would be addressed with all team members, including the other CubeSat teams that shared that P-POD. Testing may be required after the repairs depending on the extent of 
the disassembly required. If the repairs are too extensive and impact the overall schedule then a mass model could replace that CubeSat.

\subsection{Planned Integration Flow}

The ESA Education Office created a schedule for CubeSat to P-POD integration, the integrated acceptance vibration test, and delivery and integration to the launch vehicle. A Gantt chart of the planned integration schedule can be found in Section 0: Appendix A. The schedule called for the P-PODs to be delivered the second week of October 2011. During that week the P-PODs would be inspected, the connectors would be attached to their harnesses, and the final P-POD electrical interface verification documentation would be completed. The next week, the CubeSats would be delivered for final inspections and integration into the P-PODs. There would be two Cal Poly personnel that would attend these tasks.

The next task was to perform the final acceptance random vibration test, which would be performed in Toulouse, France the week of November 7, 2011. The P-PODs would be shipped with the necessary ground support equipment to the vendor facility. The P-PODs would be inspected at the test facility after the completion of the vibration testing, while the CubeSats would be inspected after the integrated P-PODs were shipped back to ESTEC. One person from Cal Poly could support this task.

The final major milestone was for the ESA Education Office to hand carry the integrated P-PODs to the launch site Kourou, French Guiana, the last week of November 2011. The Education Office scheduled for 2.5 weeks to perform inspections of the CubeSats and P-PODs, perform diagnostics and final battery charging of the CubeSats, 
closeout the P-POD access ports, apply the thermal tape to the final sides of the P-PODs, and install the P-PODs on the LSS. This would be the last access to the P-PODs or CubeSats before launch. Again, there would be one person from Cal Poly to support this task.

\subsection{Actual Integration Flow}

The reality of the nominal schedule is that very little of it held true. As the delivery date of the P-PODs to ESTEC got closer, it became likely that there would be only six CubeSats integrated into the P-PODs. However, the ESA Education Office was optimistic that all six CubeSat teams would be able to deliver their satellites to ESTEC for integration into two of the P-PODs on schedule. A Gantt chart of the actual integration schedule can be found in Section 0: Appendix B.

On October 10, 2011, one staff member from Cal Poly's CubeSat Lab and one student delivered two of the flight P-PODs to ESTEC. Since the integrated P-POD vibration testing was not until the second week of November, it was decided that if the seventh CubeSat was able to make it by then, the third P-POD could be delivered during that week; the ESA Education Office would inspect the P-PODs, the connectors would be put on the P-POD harnesses, and the documentation for the P-POD electrical interfaces would be completed.

At this point, it was clear that only one or two of the CubeSat teams would be ready for integration during the planned schedule. However, each week the ESA Education Office was still optimistic that at least one trio of CubeSats would be ready for integration into the P-POD. Since Cal Poly needed to be present for the CubeSat to P- 
POD integration to ensure it went correctly, and with some of the verification documentation incomplete, the staff member stayed at ESTEC. However, it wasn't until October 28, 2011 that the first trio of CubeSats was integrated into the P-POD. The first CubeSats to be integrated into the P-POD were XaTcobeo, e-st@r, and Goliat, shown in Figure 26 [24].

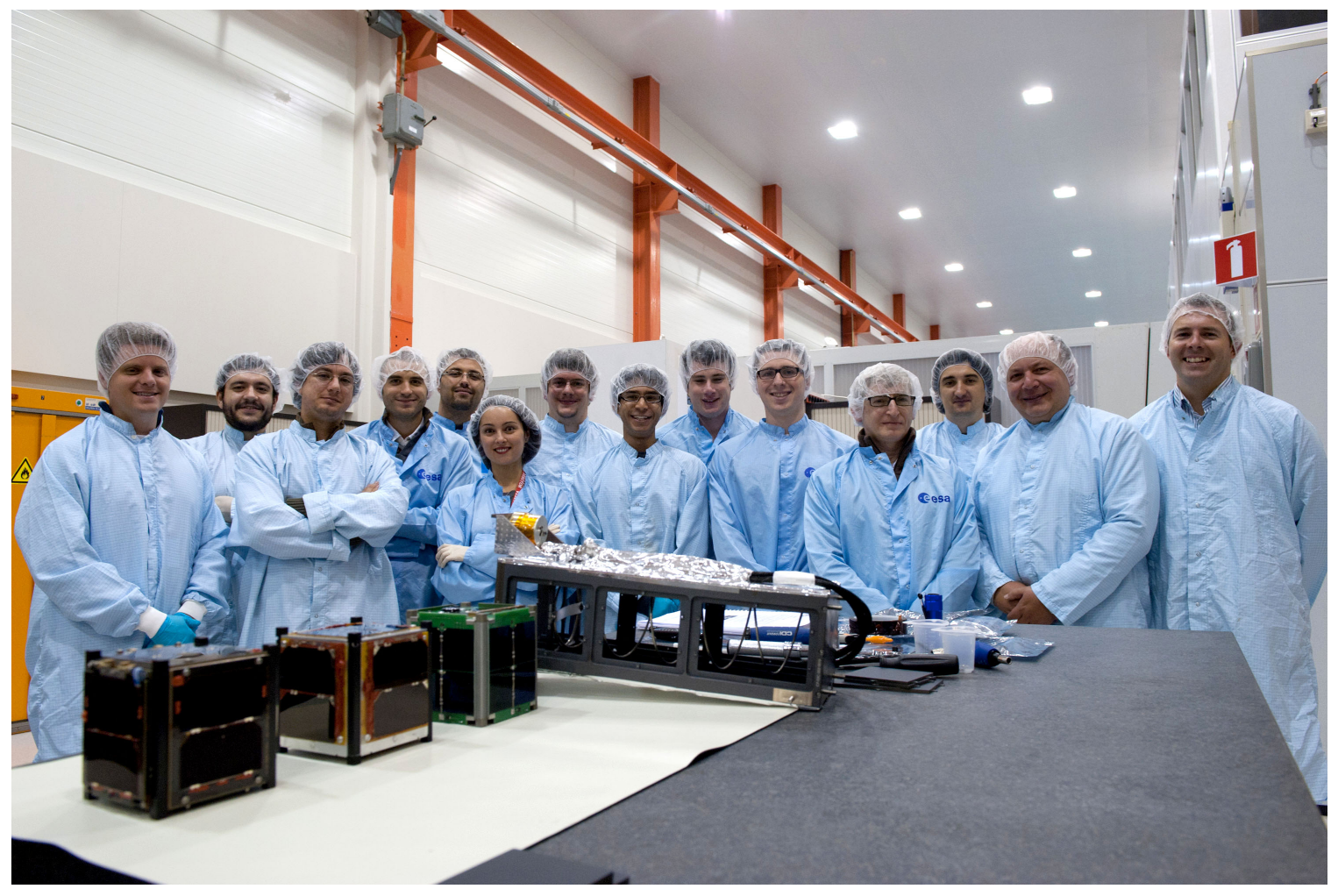

Figure 26: The XaTcobeo, e-st@r, and Goliat CubeSats with The Flight P-POD just before integration with members from their teams, the ESA Education Office and Cal Poly

Since one of the CubeSat teams in the next trio would not be able to deliver their CubeSat until the week of November 7, 2011, the Education Office decided the CubeSats would be delivered to the vibration test facility in Toulouse. At this point, it was also 
looking very promising that the seventh CubeSat would be ready for integration at least at some point before the CubeSats have to be delivered to the launch site. Cal Poly and the Education Office decided the third flight P-POD would be delivered to ESTEC by a second Cal Poly student right before the vibration testing in Toulouse. This way, the student could support the integration of the third P-POD and the testing of the first two PPODs, as a representative of Cal Poly. The second flight P-POD was integrated with PWSat, MaSat-1, and Robusta on November 9, 2011, as shown in Figure 27 [25]. The first two flight P-PODs were completed with the final acceptance testing on November 10, 2011, which was the date the ESA Education Office originally planned.

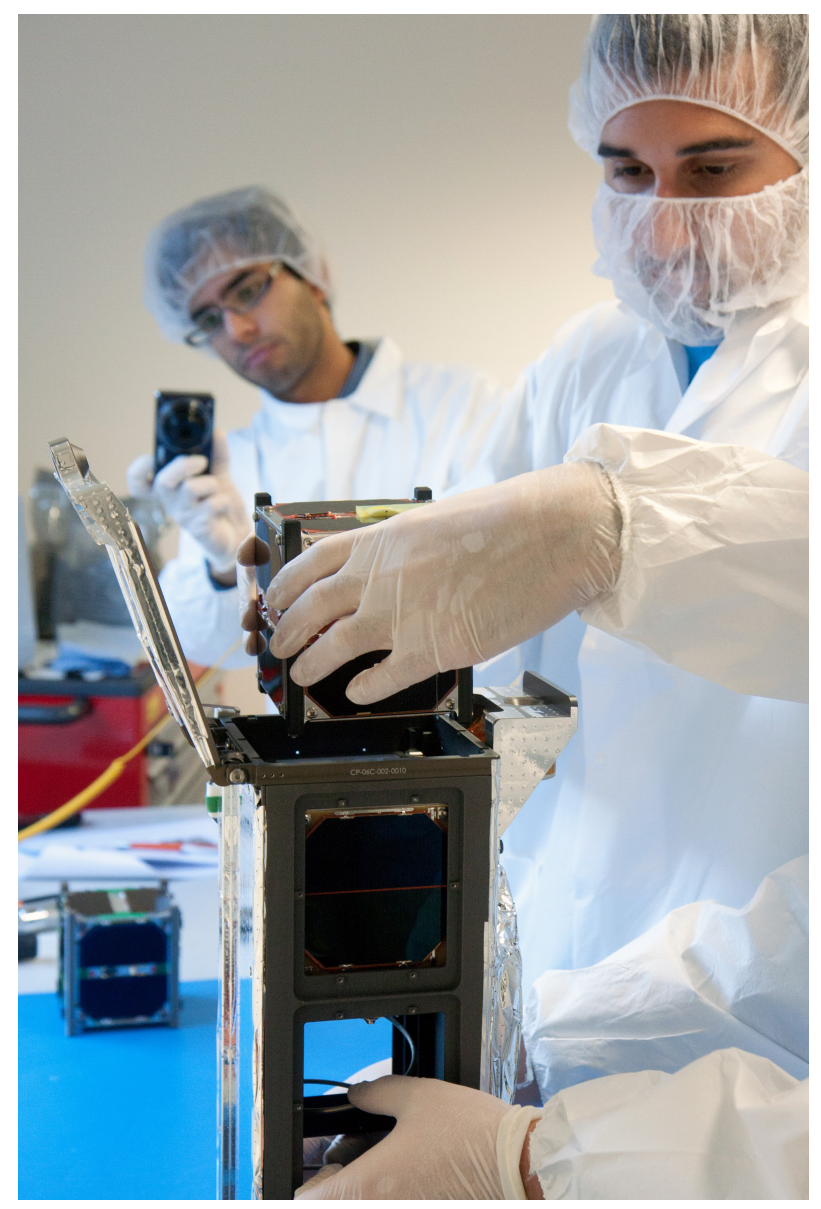

Figure 27: A Cal Poly Student Integrates MaSat-1 Into the Flight P-POD 
The seventh CubeSat, UniCubeSat-GG, encountered some delays in testing, but overcame them and was integrated into the third P-POD on November 22, 2011, shown in Figure 28 [26]. Since it was only a $1 \mathrm{U}$ CubeSat, there were two other $1 \mathrm{U}$ CubeSat mass models integrated with it. The mass models were mechanically fixed to the P-POD pusher plate so they would not deploy from the P-POD. Since the P-POD delivery date to the launch site could not be delayed, acceptance testing needed to occur right away. To save time, after the CubeSat was integrated into the P-POD, the integrated unit was handcarried to Toulouse to perform the final acceptance vibration test on November 24, 2011 by a member of the ESA Education Office and a Cal Poly staff member. The P-POD would be transported back in the morning on the 25th in order to have Cal Poly support the Flight Readiness Review (FRR) for the CubeSats and P-PODs on the Vega Maiden Flight with ASI.

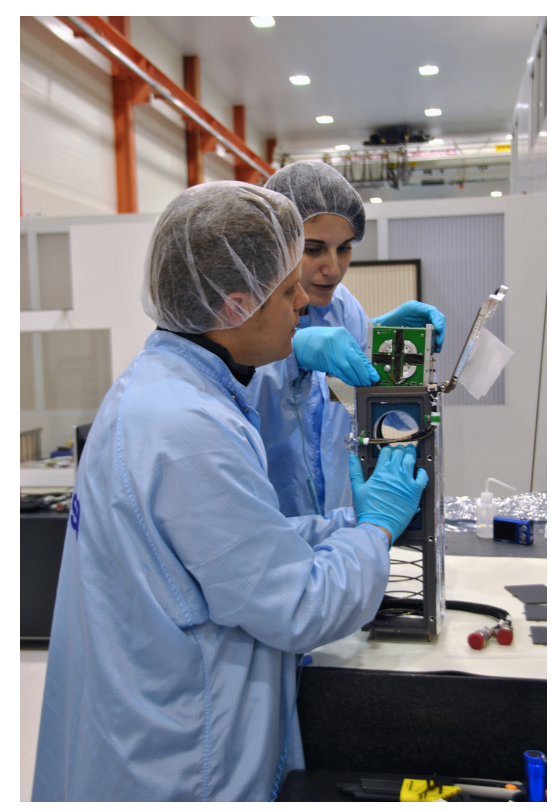

Figure 28: A Cal Poly Staff Member a UniCubeSat-GG Team Member Integrate UniCubeSat-GG into The P-POD 
The FRR with ASI was successful, and they gave approval for the integrated PPODs to be transported to the launch site; however, there were many action items that resulted from the meeting. The action items were not a surprise given that one of the PPODs had just been integrated earlier in the week and acceptance tested the day before, so there was still some documentation that needed to be completed. The integrated PPODs were hand carried to French Guiana via airplane on November 29, 2011, as scheduled. A third student from Cal Poly traveled out to French Guiana to assist with the final close out of the P-PODs. At the launch site, the CubeSat teams performed final inspections, diagnostics, and battery charging. After that, the P-POD access port covers were installed, staked, and then the last sides of the P-PODs were taped over with the thermal optical tape. Next the LSS avionics were tested to ensure the proper signals would be sent to the P-POD door release mechanisms. Last but not least, the P-PODs were integrated to the brackets on the LSS on December 13, 2011, shown in Figure 29 [27].

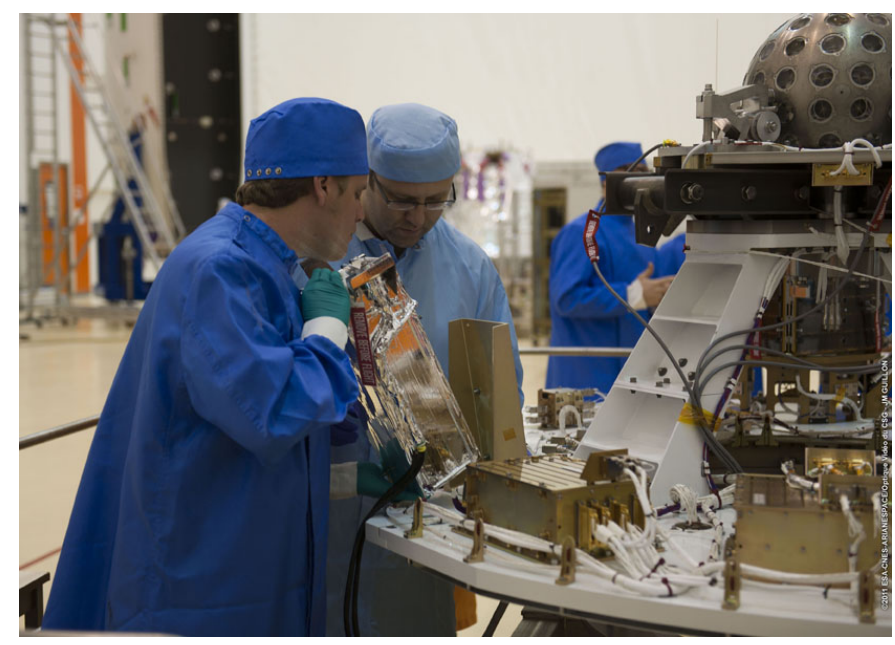

Figure 29: One of the Flight P-PODs Being Integrated to the LSS Platform by a Cal Poly Staff Member and an ASI Technician 
The LSS with LARES, ALMASat, and the three P-PODs were encapsulated in the fairing, shown in Figure 30, and integrated on the launch vehicle in January 2012 [28]. The launch incurred one more delay due to the first time processing the launch vehicle, but launched on February 13, 2012.

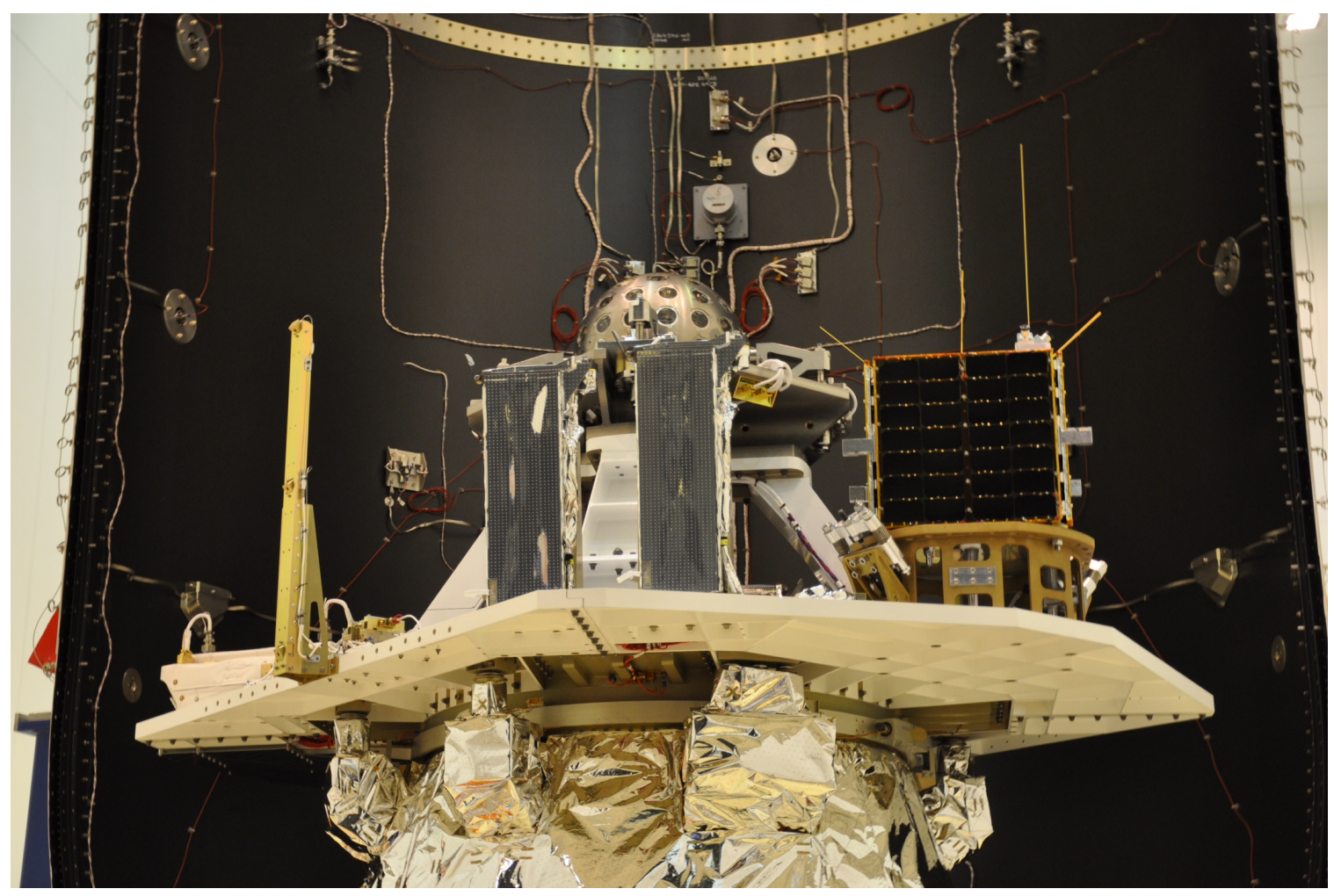

Figure 30: Two P-PODs with Thermal Tape on the LSS Just Prior to Fairing Encapsulation 


\section{CONCLUSION}

Although there were many challenges encountered throughout this launch campaign, all three P-PODs were delivered to the customer and the launch site on time. The Vega Maiden Flight occurred on February 12, 2012, as shown in Figure 31, and successfully deployed all if it's payloads on orbit [29]. This mission did require several unique solutions that have only flown on this mission: assembling the P-POD with two sets of mounting holes on different sides, and applying different thermal coatings to different faces of the P-POD. Even though there were several lengthy launch delays, which extended the launch campaign for the P-PODs more than two years, Cal Poly still had to rush in order to complete the P-POD hardware on time.

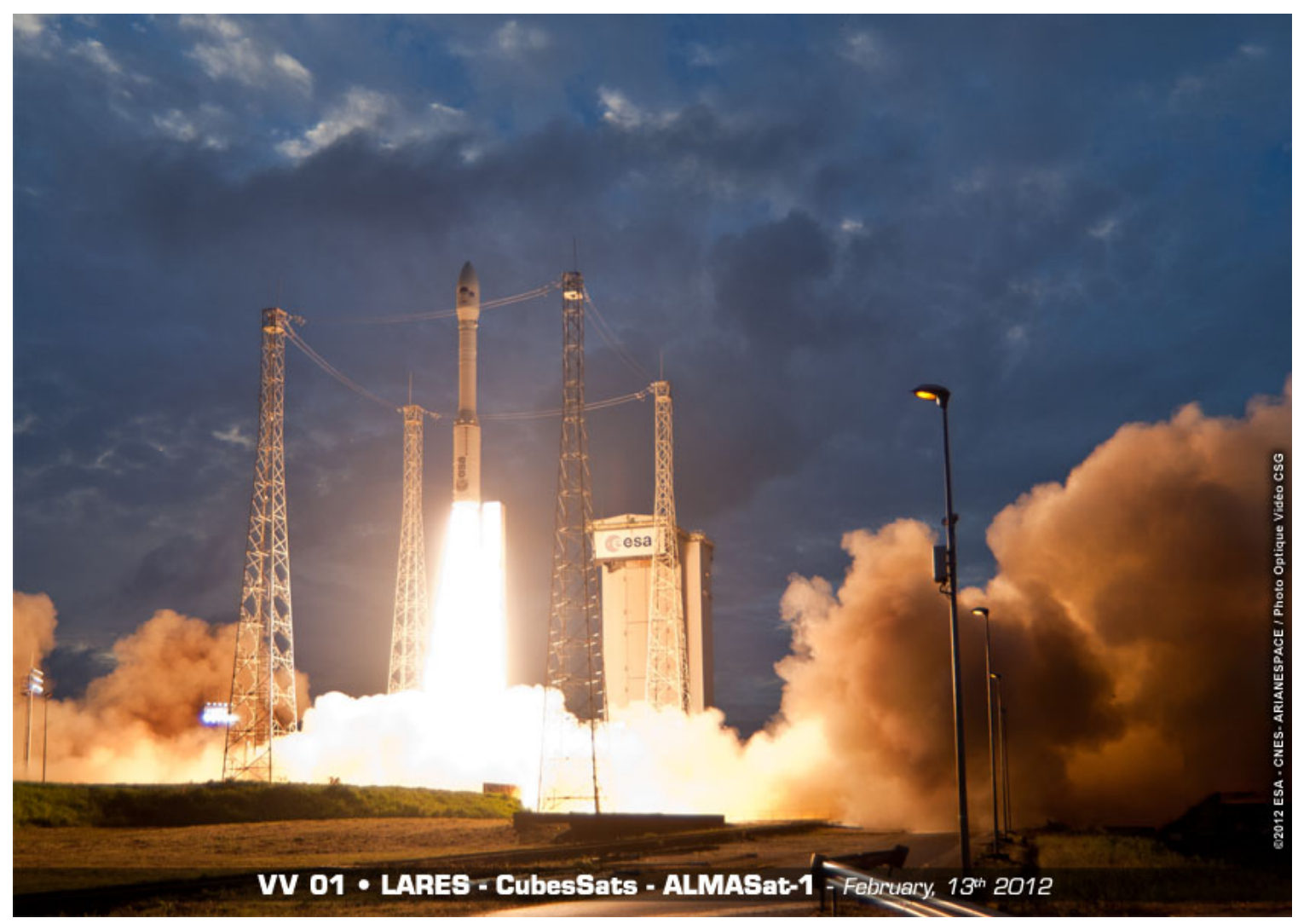

Figure 31: Picture of the Vega Maiden Flight Liftoff 
This mission had several first time milestones; it was the first launch of the Vega launch vehicle, it was the first time CubeSats had been launched by a European entity; it was the first time ESA launched CubeSats; it was the first time P-PODs had launched with ESA. One of the most important outcomes of this mission was that the ESA Education Office created the Fly Your Satellite (FYS) Program as a result of the Vega Maiden Flight's success. The FYS program is a recurring, hands-on program with the objective to compliment academic education by launching CubeSats developed by European universities [30]. Since the launch of the Vega Maiden Flight, the ESA Education Office has supported thirteen CubeSats on three different launches, and the program continues to be a success.

\subsection{Future Work}

\subsubsection{P-POD Thermal Model}

For the thermal analysis mentioned earlier, the model that was used to determine the P-POD wall temperatures was made up of only 6 nodes, one for each face. A higher fidelity thermal model of the P-POD might have yielded more favorable results, especially for the case that only modified the P-POD thermal design using washers in between the P-POD and its mounting bracket. Since there is only a minimal area of the CubeSat that interfaces with the P-POD, there is not much heat that can be exchanged though conduction. Since the CubeSat is typically the limiting factor the range of allowable temperatures, having a generic CubeSat model inside, or the ability to integrate a CubeSat thermal model into the P-POD's model, would be extremely useful. This could have saved the project thousands of dollars. 


\subsubsection{Cal Poly Team with a European Entity}

Cal Poly was able to provide P-POD hardware and integration services to ESA not only because of its reputation, but primarily because there was no European organization that could perform those tasks. There are now several European companies that can provide CubeSat dispensers with flight heritage and integration services. If $\mathrm{Cal}$ Poly still wants to fly P-PODs on ESA missions, they will have to team with a European entity in order to be able to bid on those opportunities. 
REFERENCES

[1] Mehrparvar, Arash. "CubeSat Design Specification Revision 13.” http://www.cubesat.org/resources/

[2] Lacalaca. "MaSat-1 Will Be On The First Vega Rocket.” Knights of Cydonia Region. http://cydonia.blog.hu/2011/11/19/a_masat-1_is_ott_lesz_az_elso_vega_rak

[3] Lee, Simon. Coordination of Multiple CubeSats on the Dnepr Launch Vehicle. San Luis Obispo, CA: California Polytechnic State University, 2006.

[4] Swartwout, Michael. "CubeSat Database." https://sites.google.com/a/slu.edu/swartwout/home/cubesat-database

[5] "CubeSat Concept and the Provision of Deployer Services." Earth Observation Portal. https://directory.eoportal.org/web/eoportal/satellite-missions/c-missions/cubesatconcept

[6] “AAUSat-4.” http://www.space.aau.dk/aausat4/

[7] Shirville, Graham. Klofas, Bryan. "GENSO: A Global Ground Station Network." Proceedings from the 2007 AMSat Space Symposium. Pittsburgh, PA: AMSat, 2007.

[8] Dordain, Jean-Jacques. Directorate of Launchers. Paris, France: European Space Agency, 2007.

[9] Educational Payload on the Vega Maiden Flight Call For CubeSat Proposals. Paris, France: European Space Agency, 2008. 
[10] Kyle, Ed. “Space Launch Report: ESA Vega.” Space Launch Report. http://www.spacelaunchreport.com/vega.html

[11] “LARES Mission Gallery.” LARES. http://www.lares-mission.com/gallery.html

[12] “ALMASat.” http://www.almasat.unibo.it/

[13] "Vega (Maiden Flight of new ESA Launcher and selected Payloads." Earth Observation Portal. https://directory.eoportal.org/web/eoportal/satellitemissions/v-w-x-y-z/vega

[14] "Vega Qualification Flight.” European Space Agency. http://www.esa.int/spaceinvideos/Videos/2012/01/Vega_qualification_flight

[15] Galeone, Piero. Pedersen, Jakob. “CubeSats for the Vega Maiden Flight.” 2010 Spring CubeSat Developers’ Workshop. http://mstl.atl.calpoly.edu/ workshop/archive/2010/Spring/Day\%201/

[16] "Widespread Interest for the $2^{\text {nd }}$ European CubeSat Workshop." European Space Agency. http://www.esa.int/Education/Widespread_interest_for_the_2nd_European_Cube $\underline{\text { Sat_Workshop }}$

[17] "First Vega Starts Journey to Europe's Spaceport." European Space Agency. http://www.esa.int/Our_Activities/Launchers/First_Vega_starts_journey_to_Euro pe_s_Spaceport

[18] Corvaja, S. "LARES Satellite.” European Space Agency. http://www.esa.int/spaceinimages/Images/2011/11/LARES_satellite2 
[[19] LARES - CubeSat Interface Presentation. Milan, Italy: Carlo Gavazzi Space S.p.A., 2008.

[20] "Best Practices for the Use of Sine Vibration Testing." National Aeronautics and Space Administration.

https://www.nasa.gov/sites/default/files/atoms/files/nesc tb 15-

$\underline{03 \text { best_practices_for_use_of_sine_vibration_testing.pdf }}$

[21] European Cooperation for Space Standardization Space Engineering Testing ECSS-

E-10-03A. Revision A. Noordwijk, The Netherlands: European Space Agency Publications Division, 2002.

[22] Vey, Sylvain. CubeSats: Thermal Design. Noordwijk, The Netherlands: European Space Research and Technology Centre, 2011.

[23] Pedersen, Jakob. Vannitsen, Jordan. CubeSat Educational Payload on the Vega Maiden Flight Interface Control Document. Revision 7. Noordwijk, The Netherlands: European Space Research and Technology Centre, 2011.

[24] Le Floch, A. “Teams During Preparation of the First Three CubeSats.” European Space Agency. http://www.esa.int/spaceinimages/Images/2012/02/Teams_during_preparations_o f the first three CubeSats

[25] Varga, Lajos. "Second P-POD Integration.” European Space Agency. http://www.esa.int/spaceinimages/Images/2012/02/Second_P-POD_integration2 
[26] Walker, Roger. “UniCubeSat-GG's Integration into Third P-POD.” European Space Agency. http://m.esa.int/spaceinimages/Images/2012/02/UniCubeSat_GG_s integration_in to third P-POD

[27] Guillon, J.M. “LARES, ALMASat and CubeSats Integrated.” European Space Agency. http://www.esa.int/spaceinimages/Images/2011/12/LARES_ALMASAT_and_Cu besats_integrated2

[28] "Vega payload before encapsulation in fairing." European Space Agency. http://www.esa.int/spaceinimages/Images/2012/01/Vega payload before encaps ulation_in_fairing

[29] "Liftoff of Vega VV01." European Space Agency. http://www.esa.int/spaceinimages/Images/2012/02/Liftoff_of_Vega_VV0116

[30] "Fly Your Satellite! Programme." European Space Agency. http://www.esa.int/Education/CubeSats __Fly_Your_Satellite/Fly_Your_Satellite!_programme\#history 
APPENDICES

APPENDIX A: PLANNED INTEGRATION SCHEDULE FOR THE CUBESATS ON

THE VEGA MAIDEN FLIGHT

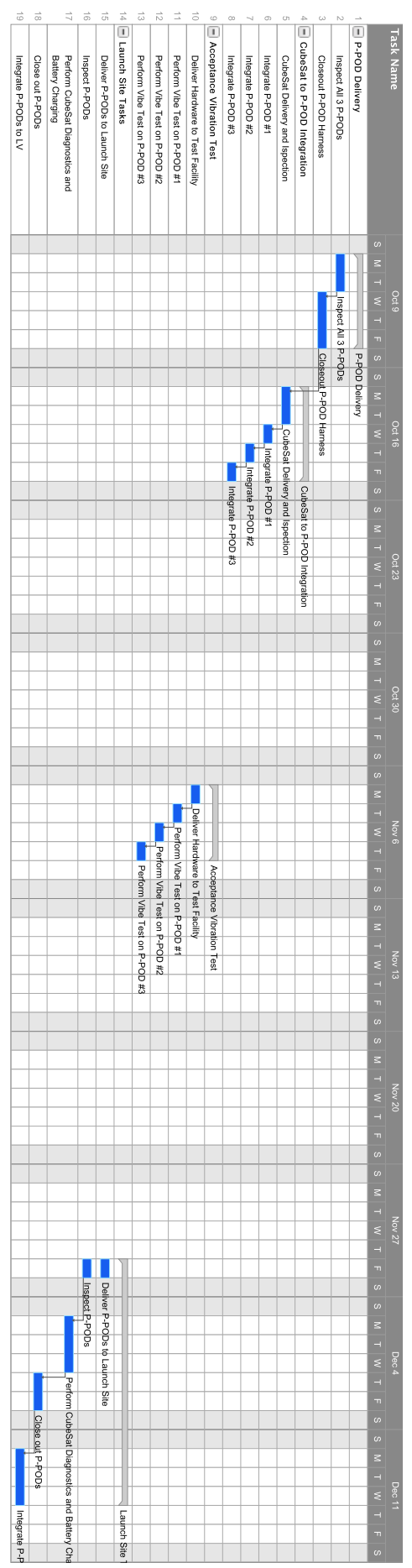


APPENDIX B: ACTUAL INTEGRATION SCHEDULE FOR THE CUBESATS ON THE VEGA MAIDEN FLIGHT

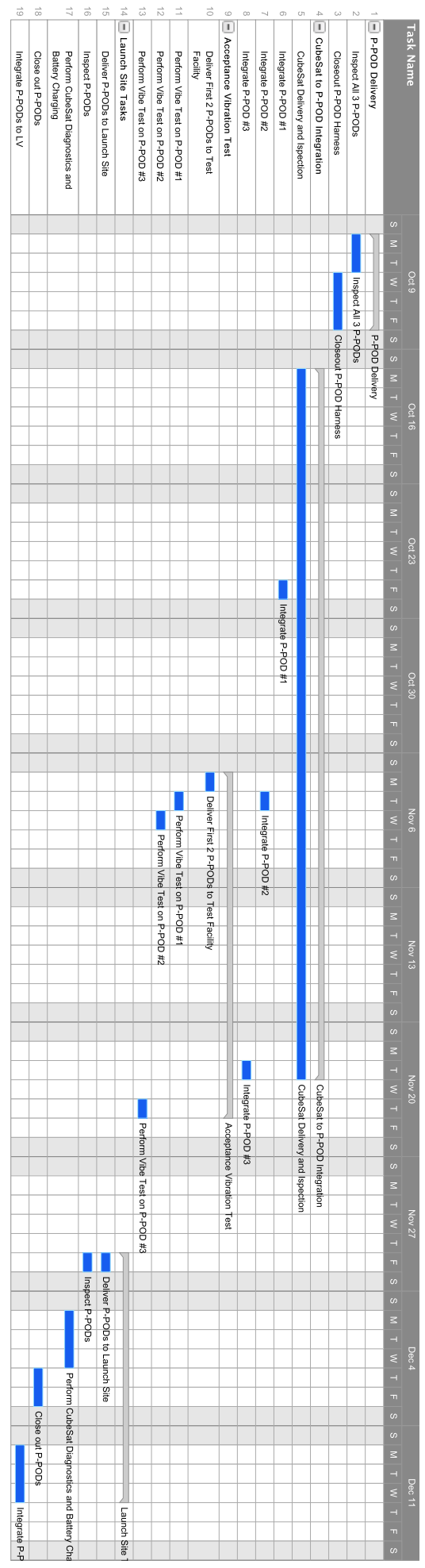

